\title{
Cryogenic Refractive Indices of S-LAH55, S-LAH55V, S-LAH59, S- LAM3, S-NBM51, S-NPH2, S-PHM52, and S-TIH14 Glasses
}

\author{
Kevin H. Miller, ${ }^{1}$ Manuel A. Quijada, and Doug Leviton \\ Goddard Space Flight Center, 8800 Greenbelt Road \\ Greenbelt, MD 20771;
}

\begin{abstract}
The Transiting Exoplanet Survey Satellite (TESS) is an explorer-class planet finder, whose principal goal is to detect small planets with bright host starts in the solar neighborhood. The TESS payload consists of four identical cameras with seven optical elements each that include various types of Ohara glass substrates. The successful implementation both panchromatic and thermal lens assembly designs for these cameras requires a fairly accurate (up to 1E-6) knowledge of the temperature and wavelength dependence of the refractive index in the wavelength and temperature range of operation. Hence, this paper is devoted to report on measurements of the refractive index over the wavelength range of $0.42-1.15$ um and temperature range of $110-310 \mathrm{~K}$ for the following Ohara glasses: S-LAH55, S-LAH55V, SLAH59, S-LAM3, S-NBM51, S-NPH2, S-PHM52, and S-TIH14. The measurements were performed utilizing the Cryogenic High Accuracy Refraction Measuring System (CHARMS) facility at NASA's Goddard Space Flight Center. A dense coverage of the absolute refractive index for the title substrates in the aforementioned wavelength and temperature ranges was used to determine the thermo-optic coefficient $(\mathrm{dn} / \mathrm{dT})$ and dispersion relation $(\mathrm{dn} / \mathrm{d} \lambda)$ as a function of wavelength and temperature. A comparison of the measured indices with literature values, specifically the temperature-dependent refractive indices of S-PHM52 and S-TIH14, will be presented.
\end{abstract}

Keywords: S-LAH55, S-LAH55V, S-LAH59, S-LAM3, S-NBM51, S-NPH2, S-PHM52, S-TIH14, CHARMS, cryogenic refractive index

\subsection{INTRODUCTION}

The Cryogenic High Accuracy Refraction Measuring System (CHARMS) was developed at Goddard Space Flight Center (GSFC), primarily in support of the James Webb Space Telescope (JWST), to measure cryogenic refractive indices (at temperatures as low as $15 \mathrm{~K}$ ) with unparalleled accuracy using minimum deviation refractometry. ${ }^{1,2}$ Using a subset of CHARMS' available wavelength and temperature capabilities, novel index measurements of eight Ohara glasses have been conducted in support of the Transiting Exoplanet Survey Satellite (TESS) mission. ${ }^{3}$ Briefly, the TESS mission is designed to detect small planets by monitoring the luminosity of a bright host stars in the solar neighborhood. As the planets transit the host star, the TESS satellite will extract information about the size, orbital period, and atmospheric signatures of the planet. The TESS payload consists of four identical cameras and a Data Handling Unit (DHU) fitted with CCD detectors and associated electronics. Each camera consist of a lens assembly with seven optical elements that include various types of Ohara glass substrates. The successful determination of the aforementioned exoplanet data relies on highly accurate knowledge of how the satellite's optical components behave over a broad wavelength range, and throughout the scope of environmental conditions encountered on orbit.

This paper reports the absolute index of refraction over the wavelength range $0.41-1.15$ um and temperature range $110-310 \mathrm{~K}$ of the following Ohara glasses: S-LAH55, S-LAH55V, S-LAH59, S-LAM3, S-NBM51, S-NPH2, SPHM52, and S-TIH14. Furthermore, two test articles, which are prisms in this report, from the same glass melt were measured to gauge intra-melt variability, and hence the consistency to which the glassmaker can produce an identical material. In this study we have observed, for the first time ever, convincing intra-melt variability on the order of a few times our uncertainty (cf. Section 4.0) for the two S-LAH55v prisms examined, and will henceforth be considered

${ }^{1}$ Author contact: Kevin.H.Miller@NASA.gov, 301-286-6628 
distinct prisms. All CHARMS measurements were taken in a high vacuum ( $\sim 1 \mathrm{e}-5$ Torr $)$ environment, so that the index of the surrounding medium is negligible.

\subsection{PRESENTATION OF MEASURED INDEX DATA}

CHARMS utilizes the exacting method of minimum deviation refractometry (light transits the prism parallel to the nonrefracting face) to obtain the real part of the refractive index, $n$. Minimum deviation refractometry has an advantage over other techniques to obtain refractive index (e.g., Kramers-Kronig transformation of broadband optical spectra) because it represents an absolute measurement. A detailed description of the data acquisition and data reduction processes of CHARMS is documented elsewhere. ${ }^{1}$ Raw index data as a function of temperature and wavelength are fit to a Sellmeier model of the following form:

$$
n^{2}(\lambda, T)=\sum_{j=1}^{3} \frac{S_{i}(T) \cdot \lambda^{2}}{\lambda^{2}-\lambda_{i}^{2}(T)},
$$

where the $\mathrm{S}_{\mathrm{i}}$ terms represent the strengths of theoretical resonance features at center frequencies defined by their respectively indexed $\lambda_{\mathrm{i}}$ 's. Assuming both the strengths and center frequencies to be a function of temperature, one can apply the first three terms of the summation $(j=3)$ to generate adequate fits of smoothly varying index spectra over temperature and wavelength space. Typical generated Sellmeier fits agree with the raw measured index values to less than our measurement uncertainties (cf. Section 4.0). The Sellmeier model has been widely successful in generating highly accurate index data within the fit's range of applicability. We stress the importance of not applying the Sellmeier fit to glasses beyond the temperature and wavelength range of applicability, as extrapolations have historically led to disappointing performances in as-built lenses. The temperature and wavelength applicability range of Sellmeier models presented in this study is $115 \mathrm{~K} \leq \mathrm{T} \leq 300 \mathrm{~K} ; 0.42 \mu \mathrm{m} \leq \lambda \leq 1.1 \mu \mathrm{m}$, respectively. Note that the applicability range of the fit is slightly smaller than the quoted measured range of $110 \mathrm{~K} \leq \mathrm{T} \leq 310 \mathrm{~K} ; 0.416 \mu \mathrm{m} \leq \lambda \leq 1.15 \mu \mathrm{m}$ to avoid uncertainties in derivatives.

\subsection{MEASUREMENT DETAILS AND FIT COEFFICIENTS}

Table 1 details the apex angle, number of independent index measurements taken, and the average value of the modulus of the difference between the raw data point and the fitted point for each independent index value. The measurement of prism apex angle is noteworthy as it uses an ultra-high resolution electronic nulling autocollimator to determine the angle between adjacent refracting faces of the prism. The apex measurement is repeated for four separate orientations spaced by $90^{\circ}$ on a spindle platform to remove any systematic errors. For the seven sets of prisms that exhibited negligible intra-melt variability, only one associated apex value is reported. Table 2 contains the temperature-dependent Sellmeier coefficients to third order. We have observed that fourth order fits have insignificant contribution to the average absolute fit residual. All 24 variables of the third order Sellmeier equation were free for optimization under the constraint that a positive overall value is generated on the left side of equation 1

Table 1. Prism ID, apex angle, number of beam deviations contributing to Sellmeier fit, and average absolute fit residual.

\begin{tabular}{|c|c|c|c|}
\hline Prism & apex angle $\left[{ }^{\circ}\right]$ & number of deviations & average absolute fit residual \\
\hline S-LAH55 & 52.31125 & 1662 & $4.4 \mathrm{E}-6$ \\
\hline S-LAH55v-1 & 52.30869 & 435 & $3.7 \mathrm{E}-6$ \\
\hline S-LAH55v-2 & 52.28301 & 739 & $3.6 \mathrm{E}-6$ \\
\hline S-LAH59 & 50.998397 & 764 & $3.6 \mathrm{E}-6$ \\
\hline S-LAM3 & 58.002741 & 1811 & $3.7 \mathrm{E}-6$ \\
\hline S-NBM51 & 58.99676 & 575 & $2.6 \mathrm{E}-6$ \\
\hline S-NPH2 & 46.23005 & 2561 & $7.1 \mathrm{E}-6$ \\
\hline S-PHM52 & 59.036378 & 613 & $3.5 \mathrm{E}-6$ \\
\hline S-TIH14 & 54.003584 & 680 & $5.2 \mathrm{E}-6$ \\
\hline
\end{tabular}


Table 2. Coefficients for the temperature-dependent Sellmeier fit of absolute refractive of S-LAH55, S-LAH55v-1, SLAH55v-2, S-LAH59, S-LAM3, S-NBM51, S-NPH2, S-PHM52, and S-TIH14.

\begin{tabular}{|c|c|c|c|c|c|c|}
\hline \multicolumn{7}{|c|}{ Coefficients for the temperature dependent Sellmeier equation for S-LAH55 } \\
\hline Term & 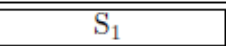 & $\overline{\mathrm{S}_{2}}$ & $\overline{\mathrm{S}_{3}}$ & 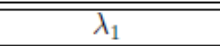 & $\overline{\lambda_{2}}$ & 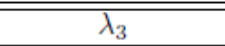 \\
\hline $\mathrm{T}^{0}$ & $1.7814312 \mathrm{E}+00$ & $4.9636074 \mathrm{E}-01$ & $1.1689227 \mathrm{E}+01$ & $-9.1108620 \mathrm{E}-02$ & $1.7936965 \mathrm{E}-01$ & $2.7903905 \mathrm{E}+01$ \\
\hline $\mathrm{T}^{1}$ & $6.3081385 \mathrm{E}-04$ & $-6.2964009 \mathrm{E}-04$ & $-2.3610072 \mathrm{E}-02$ & $-1.5775242 \mathrm{E}-05$ & $6.0360844 \mathrm{E}-05$ & $-2.9769503 \mathrm{E}-02$ \\
\hline $\mathrm{T}^{2}$ & $-1.4402478 \mathrm{E}-07$ & $1.0040833 \mathrm{E}-07$ & $-1.3222486 \mathrm{E}-05$ & $-5.9958893 \mathrm{E}-08$ & $-8.7187023 \mathrm{E}-08$ & $-1.8651425 \mathrm{E}-05$ \\
\hline $\mathrm{T}^{3}$ & $4.8110326 \mathrm{E}-10$ & $-3.6453859 \mathrm{E}-10$ & $4.4735868 \mathrm{E}-08$ & $7.5442724 \mathrm{E}-11$ & $2.3594691 \mathrm{E}-10$ & $1.1616431 \mathrm{E}-08$ \\
\hline \multicolumn{7}{|c|}{ Coefficients for the temperature dependent Sellmeier equation for S-LAH55v-1 } \\
\hline Term & $\mathrm{S}_{1}$ & $\overline{\mathrm{S}_{2}}$ & $\overline{\mathrm{S}} \mathrm{S}_{3}$ & $\lambda_{1}$ & $\lambda_{2}$ & $\lambda_{3}$ \\
\hline $\mathrm{T}^{0}$ & $1.3062627 \mathrm{E}+00$ & $9.7168551 \mathrm{E}-01$ & $2.4009377 \mathrm{E}+02$ & $6.2944667 \mathrm{E}-02$ & 1.6209107E-01 & $1.4070905 \mathrm{E}+02$ \\
\hline $\mathrm{T}^{1}$ & $1.0228418 \mathrm{E}-03$ & $-1.0290658 \mathrm{E}-03$ & $2.6319867 \mathrm{E}-01$ & $9.8285075 \mathrm{E}-05$ & $2.0042243 \mathrm{E}-05$ & $-3.5636616 \mathrm{E}-01$ \\
\hline $\mathrm{T}^{2}$ & $7.8361832 \mathrm{E}-08$ & $-8.3012365 \mathrm{E}-08$ & $5.5493309 \mathrm{E}-04$ & $-1.5925496 \mathrm{E}-07$ & $7.4690875 \mathrm{E}-08$ & $4.9573129 \mathrm{E}-03$ \\
\hline $\mathrm{T}^{3}$ & $1.5600631 \mathrm{E}-10$ & $-1.0041150 \mathrm{E}-10$ & $6.4871588 \mathrm{E}-05$ & $1.9912890 \mathrm{E}-10$ & $-3.4200100 \mathrm{E}-11$ & $-3.7136888 \mathrm{E}-06$ \\
\hline \multicolumn{7}{|c|}{ Coefficients for the temperature dependent Sellmeier equation for S-LAH55v-2 } \\
\hline Term & 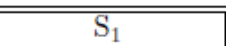 & $\overline{\mathrm{S}_{2}}$ & $\mathrm{~S}_{3}$ & $\lambda_{1}$ & $\lambda_{2}$ & $\overline{\lambda_{3}}$ \\
\hline $\mathrm{T}^{0}$ & $1.3018347 \mathrm{E}+00$ & $9.7505234 \mathrm{E}-01$ & $1.0286210 \mathrm{E}+03$ & $6.5864273 \mathrm{E}-02$ & 1.6033872E-01 & $2.6191686 \mathrm{E}+02$ \\
\hline $\mathrm{T}^{1}$ & $1.0356899 \mathrm{E}-03$ & $-1.0224733 \mathrm{E}-03$ & 6.6798131E-01 & $5.1890577 \mathrm{E}-05$ & $4.4572811 \mathrm{E}-05$ & $1.9099141 \mathrm{E}-01$ \\
\hline $\mathrm{T}^{2}$ & $1.3179965 \mathrm{E}-07$ & $-2.3043813 \mathrm{E}-07$ & $3.0365432 \mathrm{E}-02$ & $7.0075876 \mathrm{E}-08$ & $-4.6941224 \mathrm{E}-08$ & $2.7055936 \mathrm{E}-03$ \\
\hline $\mathrm{T}^{3}$ & $1.0322643 \mathrm{E}-09$ & $-8.3254570 \mathrm{E}-10$ & $-4.6199578 \mathrm{E}-05$ & $-1.1736863 \mathrm{E}-10$ & $2.1825153 \mathrm{E}-10$ & $-4.9489012 \mathrm{E}-06$ \\
\hline \multicolumn{7}{|c|}{ Coefficients for the temperature dependent Sellmeier equation for S-LAH59 } \\
\hline Term & $\overline{\mathrm{S}_{1}}$ & $\overline{\mathrm{S}_{2}}$ & $\overline{\mathrm{S}_{3}}$ & $\overline{\lambda_{1}}$ & $\lambda_{2}$ & $\overline{\lambda_{3}}$ \\
\hline $\mathrm{T}^{0}$ & $1.6461568 \mathrm{E}+00$ & $5.7161590 \mathrm{E}-01$ & $6.1671927 \mathrm{E}+02$ & $8.8046126 \mathrm{E}-02$ & 1.6332093E-01 & $7.1772194 \mathrm{E}+01$ \\
\hline $\mathrm{T}^{1}$ & $-1.4205520 \mathrm{E}-03$ & $1.4168758 \mathrm{E}-03$ & $-6.0378670 \mathrm{E}+00$ & $-5.2899964 \mathrm{E}-05$ & $-6.7797001 \mathrm{E}-05$ & $2.4641898 \mathrm{E}+00$ \\
\hline $\mathrm{T}^{2}$ & $2.4295545 \mathrm{E}-08$ & $-2.4490122 \mathrm{E}-08$ & $1.6849620 \mathrm{E}-01$ & $2.5069996 \mathrm{E}-08$ & $9.2972146 \mathrm{E}-08$ & $6.8159459 \mathrm{E}-03$ \\
\hline $\mathrm{T}^{3}$ & $2.0805207 \mathrm{E}-11$ & $2.6396865 \mathrm{E}-11$ & $3.0619744 \mathrm{E}-04$ & $-1.8706535 \mathrm{E}-10$ & $-6.1581196 \mathrm{E}-11$ & $-5.5960325 \mathrm{E}-06$ \\
\hline \multicolumn{7}{|c|}{ Coefficients for the temperature dependent Sellmeier equation for S-LAM3 } \\
\hline Term & 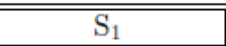 & 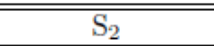 & 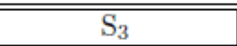 & $\lambda_{1}$ & $\lambda_{2}$ & $\overline{\lambda_{3}}$ \\
\hline $\mathrm{T}^{0}$ & $1.4826244 \mathrm{E}+00$ & $4.0512531 \mathrm{E}-01$ & $1.5622686 \mathrm{E}+01$ & $8.2279692 \mathrm{E}-02$ & $1.7272586 \mathrm{E}-01$ & $3.0588013 \mathrm{E}+01$ \\
\hline $\mathrm{T}^{1}$ & $-9.4286696 \mathrm{E}-04$ & $9.2857283 \mathrm{E}-04$ & $1.3329059 \mathrm{E}-02$ & $-6.3123886 \mathrm{E}-06$ & $-8.9609891 \mathrm{E}-05$ & $1.7317141 \mathrm{E}-01$ \\
\hline $\mathrm{T}^{2}$ & $1.3596120 \mathrm{E}-08$ & $-1.6758711 \mathrm{E}-08$ & $1.3452161 \mathrm{E}-03$ & $-2.2317324 \mathrm{E}-07$ & $2.1857831 \mathrm{E}-07$ & $7.4685318 \mathrm{E}-04$ \\
\hline $\mathrm{T}^{3}$ & $-7.4262754 \mathrm{E}-12$ & $3.1970147 \mathrm{E}-11$ & $2.0998717 \mathrm{E}-06$ & $2.9718159 \mathrm{E}-10$ & $-2.8694307 \mathrm{E}-10$ & $-5.2991917 \mathrm{E}-07$ \\
\hline \multicolumn{7}{|c|}{ Coefficients for the temperature dependent Sellmeier equation for S-NBM51 } \\
\hline Term & 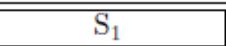 & 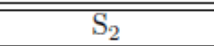 & 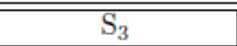 & $\overline{\lambda_{1}}$ & $\overline{\lambda_{2}}$ & 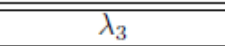 \\
\hline $\mathrm{T}^{\mathrm{0}}$ & $1.3458658 \mathrm{E}+00$ & $2.0491569 \mathrm{E}-01$ & $1.3552138 \mathrm{E}+03$ & $9.0893927 \mathrm{E}-02$ & $1.9468659 \mathrm{E}-01$ & $1.9486831 \mathrm{E}+02$ \\
\hline $\mathrm{T}^{1}$ & $-5.5343214 \mathrm{E}-04$ & $5.3830009 \mathrm{E}-04$ & $-1.0474619 \mathrm{E}+01$ & $-3.9145690 \mathrm{E}-05$ & $-6.6986338 \mathrm{E}-05$ & $1.2913173 \mathrm{E}+00$ \\
\hline $\mathrm{T}^{2}$ & $4.3335356 \mathrm{E}-08$ & $1.2482884 \mathrm{E}-08$ & $1.4806369 \mathrm{E}-01$ & $-2.9969003 \mathrm{E}-08$ & $6.5151082 \mathrm{E}-08$ & $6.3857490 \mathrm{E}-03$ \\
\hline $\mathrm{T}^{3}$ & $-8.9902143 \mathrm{E}-11$ & $3.4821788 \mathrm{E}-11$ & $-1.3206530 \mathrm{E}-05$ & $6.2606612 \mathrm{E}-11$ & $-5.6106312 \mathrm{E}-11$ & $-6.8968628 \mathrm{E}-06$ \\
\hline \multicolumn{7}{|c|}{$\begin{array}{l}\text { Coefficients for the temperature dependent Sellmeier equation for S-NPH2 } \\
\end{array}$} \\
\hline Term & 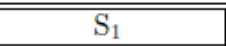 & 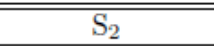 & 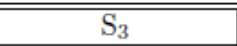 & $\overline{\lambda \lambda_{1}}$ & $\lambda_{2}$ & $\lambda_{3}$ \\
\hline $\mathrm{T}^{0}$ & $2.0496807 \mathrm{E}+00$ & $4.3306230 \mathrm{E}-01$ & $9.3056880 \mathrm{E}+04$ & $1.3167285 \mathrm{E}-01$ & $2.7198343 \mathrm{E}-01$ & $2.3022307 \mathrm{E}+03$ \\
\hline $\mathrm{T}^{1}$ & $-7.3401242 \mathrm{E}-04$ & 7.3348479E-04 & $-2.5056619 \mathrm{E}+02$ & $-6.3061282 \mathrm{E}-05$ & $-5.1081866 \mathrm{E}-05$ & $-2.9208334 \mathrm{E}+00$ \\
\hline $\mathrm{T}^{2}$ & $1.3743570 \mathrm{E}-06$ & $-1.4502751 \mathrm{E}-06$ & $2.3200182 \mathrm{E}+00$ & $1.0822474 \mathrm{E}-07$ & $1.1816101 \mathrm{E}-07$ & $2.9506005 \mathrm{E}-02$ \\
\hline $\mathrm{T}^{3}$ & $1.6697648 \mathrm{E}-09$ & $-1.5577186 \mathrm{E}-09$ & $-1.6768322 \mathrm{E}-03$ & $1.7084946 \mathrm{E}-10$ & $1.2060562 \mathrm{E}-10$ & $-3.1050016 \mathrm{E}-05$ \\
\hline \multicolumn{7}{|c|}{ Coefficients for the temperature dependent Sellmeier equation for S-PHM52 } \\
\hline Term & 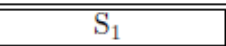 & 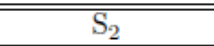 & 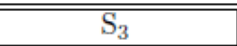 & $\overline{\lambda_{1}}$ & $\lambda_{2}$ & $\overline{\lambda_{3}}$ \\
\hline $\mathrm{T}^{0}$ & $1.4269760 \mathrm{E}+00$ & $1.5906485 \mathrm{E}-01$ & $8.1106397 \mathrm{E}+03$ & $8.4791006 \mathrm{E}-02$ & $1.5587797 \mathrm{E}-01$ & $6.5493712 \mathrm{E}+02$ \\
\hline $\mathrm{T}^{1}$ & $-3.3180935 \mathrm{E}-04$ & $2.9417595 \mathrm{E}-04$ & $-1.5445555 \mathrm{E}+01$ & $2.9050286 \mathrm{E}-06$ & $-2.5485357 \mathrm{E}-05$ & $5.0312765 \mathrm{E}+00$ \\
\hline $\mathrm{T}^{2}$ & $5.5678574 \mathrm{E}-08$ & $2.1658948 \mathrm{E}-08$ & $7.0698412 \mathrm{E}-01$ & $-1.3044013 \mathrm{E}-07$ & $1.0829095 \mathrm{E}-07$ & $5.8916151 \mathrm{E}-03$ \\
\hline $\mathrm{T}^{3}$ & $-1.7389067 \mathrm{E}-10$ & $6.2704518 \mathrm{E}-11$ & $-3.4838125 \mathrm{E}-04$ & $2.8823528 \mathrm{E}-10$ & $-3.4082585 \mathrm{E}-10$ & $-4.7205580 \mathrm{E}-06$ \\
\hline \multicolumn{7}{|c|}{ Coefficients for the temperature dependent Sellmeier equation for S-TIH14 } \\
\hline Term & 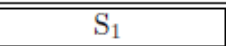 & 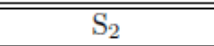 & 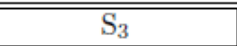 & 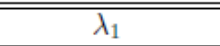 & $\lambda_{2}$ & 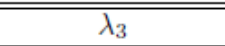 \\
\hline $\mathrm{T}^{0}$ & $1.6817785 \mathrm{E}+00$ & $3.0485459 \mathrm{E}-01$ & $1.1533205 \mathrm{E}+03$ & $1.1001600 \mathrm{E}-01$ & $2.4689603 \mathrm{E}-01$ & $2.4133481 \mathrm{E}+02$ \\
\hline $\mathrm{T}^{1}$ & $-3.1770188 \mathrm{E}-06$ & $-3.2989806 \mathrm{E}-05$ & $-5.7639062 \mathrm{E}+00$ & $2.6861818 \mathrm{E}-05$ & $-1.7792087 \mathrm{E}-05$ & $1.4409381 \mathrm{E}-01$ \\
\hline $\mathrm{T}^{2}$ & 1.6435249E-06 & $-1.5648077 \mathrm{E}-06$ & $6.8571853 \mathrm{E}-02$ & $3.4871219 \mathrm{E}-08$ & $3.0572590 \mathrm{E}-07$ & $8.5059967 \mathrm{E}-03$ \\
\hline $\mathrm{T}^{3}$ & $-5.4877509 \mathrm{E}-09$ & 5.4293502E-09 & $1.0160805 \mathrm{E}-04$ & $-3.3309559 \mathrm{E}-10$ & $-7.9767883 \mathrm{E}-10$ & $-7.9408637 \mathrm{E}-06$ \\
\hline
\end{tabular}




\subsection{MEASUREMENT UNCERTAINTIES AND RESULTS}

Table 3. Calculated uncertainties for respective prisms.

\begin{tabular}{|c|c|c|c|c|c|}
\hline \multicolumn{6}{|c|}{ S-LAH55 } \\
\hline "Wavelength $[\mu \mathrm{m}]$ & $120 \mathrm{~K}$ & $150 \mathrm{~K}$ & $200 \mathrm{~K}$ & $250 \mathrm{~K}$ & $300 \mathrm{~K}$ \\
\hline 0.46 & $2.5 \mathrm{E}-5$ & & $2.7 \mathrm{E}-5$ & $2.6 \mathrm{E}-5$ & $2.6 \mathrm{E}-5$ \\
\hline 0.63 & $1.5 \mathrm{E}-5$ & & $1.5 \mathrm{E}-5$ & $1.5 \mathrm{E}-5$ & $1.5 \mathrm{E}-5$ \\
\hline 0.80 & $1.4 \mathrm{E}-5$ & & $1.3 \mathrm{E}-5$ & $1.3 \mathrm{E}-5$ & $1.3 \mathrm{E}-5$ \\
\hline 1.10 & $1.3 \mathrm{E}-5$ & & $1.2 \mathrm{E}-5$ & $1.3 \mathrm{E}-5$ & $1.2 \mathrm{E}-5$ \\
\hline \multicolumn{6}{|c|}{ S-LAH55v-1 } \\
\hline Wavelength $[\mu \mathrm{m}]$ & $120 \mathrm{~K}$ & $150 \mathrm{~K}$ & $200 \mathrm{~K}$ & $250 \mathrm{~K}$ & $300 \mathrm{~K}$ \\
\hline 0.46 & $2.2 \mathrm{E}-5$ & $2.3 \mathrm{E}-5$ & $2.3 \mathrm{E}-5$ & $2.3 \mathrm{E}-5$ & $2.3 \mathrm{E}-5$ \\
\hline 0.63 & $8.9 \mathrm{E}-6$ & $9.5 \mathrm{E}-6$ & $9.4 \mathrm{E}-6$ & $9.8 \mathrm{E}-6$ & $9.4 \mathrm{E}-6$ \\
\hline 0.79 & $5.4 \mathrm{E}-6$ & $6.2 \mathrm{E}-6$ & $6.4 \mathrm{E}-6$ & $6.4 \mathrm{E}-6$ & $6.0 \mathrm{E}-6$ \\
\hline 1.01 & $4.5 \mathrm{E}-6$ & $4.5 \mathrm{E}-6$ & $4.5 \mathrm{E}-6$ & $4.9 \mathrm{E}-6$ & $4.9 \mathrm{E}-6$ \\
\hline \multicolumn{6}{|c|}{ "S-LAH55v-2 } \\
\hline Wavelength $[\mu \mathrm{m}]$ & $120 \mathrm{~K}$ & $150 \mathrm{~K}$ & $200 \mathrm{~K}$ & $250 \mathrm{~K}$ & $300 \mathrm{~K}$ \\
\hline 0.46 & $2.2 \mathrm{E}-5$ & $2.3 \mathrm{E}-5$ & $2.3 \mathrm{E}-5$ & $2.3 \mathrm{E}-5$ & $2.3 \mathrm{E}-5$ \\
\hline 0.63 & $8.9 \mathrm{E}-6$ & $9.5 \mathrm{E}-6$ & $9.4 \mathrm{E}-6$ & $9.8 \mathrm{E}-6$ & $9.4 \mathrm{E}-6$ \\
\hline 0.79 & $5.4 \mathrm{E}-6$ & $6.2 \mathrm{E}-6$ & $6.4 \mathrm{E}-6$ & $6.4 \mathrm{E}-6$ & $6.0 \mathrm{E}-6$ \\
\hline 1.01 & $4.5 \mathrm{E}-6$ & $4.5 \mathrm{E}-6$ & $4.5 \mathrm{E}-6$ & $4.9 \mathrm{E}-6$ & $4.9 \mathrm{E}-6$ \\
\hline \multicolumn{6}{|c|}{ S-LAH59 } \\
\hline "Wavelength $[\mu \mathrm{m}]$ & $120 \mathrm{~K}$ & $150 \mathrm{~K}$ & $200 \mathrm{~K}$ & $250 \mathrm{~K}$ & $300 \mathrm{~K}$ \\
\hline 0.45 & $2.4 \mathrm{E}-5$ & $2.3 \mathrm{E}-5$ & $2.3 \mathrm{E}-5$ & $2.2 \mathrm{E}-5$ & $2.1 \mathrm{E}-5$ \\
\hline 0.63 & $9.4 \mathrm{E}-6$ & $8.8 \mathrm{E}-6$ & $9.2 \mathrm{E}-6$ & $9.0 \mathrm{E}-6$ & $8.5 \mathrm{E}-6$ \\
\hline 0.80 & $6.9 \mathrm{E}-6$ & $5.8 \mathrm{E}-6$ & $6.3 \mathrm{E}-6$ & $6.3 \mathrm{E}-6$ & $5.9 \mathrm{E}-6$ \\
\hline 1.00 & $6.5 \mathrm{E}-6$ & $4.3 \mathrm{E}-6$ & $5.1 \mathrm{E}-6$ & $5.1 \mathrm{E}-6$ & $4.8 \mathrm{E}-6$ \\
\hline \multicolumn{6}{|c|}{ S-LAM3 } \\
\hline Wavelength $[\mu \mathrm{m}]$ & $100 \mathrm{~K}$ & $150 \mathrm{~K}$ & $200 \mathrm{~K}$ & $250 \mathrm{~K}$ & $300 \mathrm{~K}$ \\
\hline 0.46 & $3.2 \mathrm{E}-5$ & $2.3 \mathrm{E}-5$ & $2.0 \mathrm{E}-5$ & $1.7 \mathrm{E}-5$ & $1.7 \mathrm{E}-5$ \\
\hline 0.63 & $2.5 \mathrm{E}-5$ & $1.4 \mathrm{E}-5$ & $1.0 \mathrm{E}-5$ & $8.2 \mathrm{E}-6$ & $7.1 \mathrm{E}-6$ \\
\hline 0.79 & $2.4 \mathrm{E}-5$ & $1.2 \mathrm{E}-5$ & $8.2 \mathrm{E}-6$ & $5.9 \mathrm{E}-6$ & $4.6 \mathrm{E}-6$ \\
\hline 1.01 & $2.3 \mathrm{E}-5$ & $1.2 \mathrm{E}-5$ & $7.6 \mathrm{E}-6$ & $5.2 \mathrm{E}-6$ & $3.9 \mathrm{E}-6$ \\
\hline \multicolumn{6}{|c|}{ S-NBM51 } \\
\hline Wavelength $[\mu \mathrm{m}]$ & $130 \mathrm{~K}$ & $150 \mathrm{~K}$ & $200 \mathrm{~K}$ & $250 \mathrm{~K}$ & $300 \mathrm{~K}$ \\
\hline 0.45 & $1.7 \mathrm{E}-5$ & $1.7 \mathrm{E}-5$ & $1.8 \mathrm{E}-5$ & $1.8 \mathrm{E}-5$ & $1.7 \mathrm{E}-5$ \\
\hline 0.63 & $7.1 \mathrm{E}-6$ & $6.7 \mathrm{E}-6$ & $6.6 \mathrm{E}-6$ & $6.8 \mathrm{E}-6$ & $6.5 \mathrm{E}-6$ \\
\hline 0.80 & $4.6 \mathrm{E}-6$ & $5.1 \mathrm{E}-6$ & $4.5 \mathrm{E}-6$ & $4.8 \mathrm{E}-6$ & $4.5 \mathrm{E}-6$ \\
\hline 1.00 & $4.6 \mathrm{E}-6$ & $4.5 \mathrm{E}-6$ & $3.6 \mathrm{E}-6$ & $4.0 \mathrm{E}-6$ & $3.8 \mathrm{E}-6$ \\
\hline \multicolumn{6}{|c|}{ S-NPH2 } \\
\hline Wavelength $[\mu \mathrm{m}]$ & $120 \mathrm{~K}$ & $150 \mathrm{~K}$ & $200 \mathrm{~K}$ & $250 \mathrm{~K}$ & $300 \mathrm{~K}$ \\
\hline 0.46 & $2.1 \mathrm{E}-4$ & $7.1 \mathrm{E}-5$ & $6.5 \mathrm{E}-5$ & $6.6 \mathrm{E}-5$ & $6.6 \mathrm{E}-5$ \\
\hline 0.63 & $4.1 \mathrm{E}-5$ & $3.2 \mathrm{E}-5$ & $2.7 \mathrm{E}-5$ & $2.4 \mathrm{E}-5$ & $2.4 \mathrm{E}-5$ \\
\hline 0.80 & $3.9 \mathrm{E}-5$ & $2.8 \mathrm{E}-5$ & $2.2 \mathrm{E}-5$ & $2.0 \mathrm{E}-5$ & $1.8 \mathrm{E}-5$ \\
\hline 1.10 & $3.3 \mathrm{E}-5$ & $2.5 \mathrm{E}-5$ & $2.1 \mathrm{E}-5$ & $1.9 \mathrm{E}-5$ & $1.7 \mathrm{E}-5$ \\
\hline \multicolumn{6}{|c|}{ "S-PHM52 } \\
\hline "Wavelength $[\mu \mathrm{m}]$ & $115 \mathrm{~K}$ & $150 \mathrm{~K}$ & $200 \mathrm{~K}$ & $250 \mathrm{~K}$ & $300 \mathrm{~K}$ \\
\hline 0.46 & $3.5 \mathrm{E}-5$ & $2.4 \mathrm{E}-5$ & $1.7 \mathrm{E}-5$ & $1.4 \mathrm{E}-5$ & $1.2 \mathrm{E}-5$ \\
\hline 0.63 & $3.0 \mathrm{E}-5$ & $1.8 \mathrm{E}-5$ & $1.1 \mathrm{E}-5$ & $5.0 \mathrm{E}-6$ & $5.8 \mathrm{E}-6$ \\
\hline 0.80 & $2.7 \mathrm{E}-5$ & $1.7 \mathrm{E}-5$ & $9.8 \mathrm{E}-6$ & $6.5 \mathrm{E}-6$ & $4.7 \mathrm{E}-6$ \\
\hline 1.00 & $2.3 \mathrm{E}-5$ & $1.6 \mathrm{E}-5$ & $9.5 \mathrm{E}-6$ & $6.0 \mathrm{E}-6$ & $4.3 \mathrm{E}-6$ \\
\hline \multicolumn{6}{|c|}{ S-TIH14 } \\
\hline Wavelength $[\mu \mathrm{m}]$ & $130 \mathrm{~K}$ & $150 \mathrm{~K}$ & $200 \mathrm{~K}$ & $250 \mathrm{~K}$ & $300 \mathrm{~K}$ \\
\hline 0.45 & $4.5 \mathrm{E}-5$ & $4.0 \mathrm{E}-5$ & $3.7 \mathrm{E}-5$ & $3.7 \mathrm{E}-5$ & $3.7 \mathrm{E}-5$ \\
\hline 0.63 & $2.4 \mathrm{E}-5$ & $1.8 \mathrm{E}-5$ & $1.3 \mathrm{E}-5$ & $1.2 \mathrm{E}-5$ & $1.1 \mathrm{E}-5$ \\
\hline 0.80 & $2.0 \mathrm{E}-5$ & $1.4 \mathrm{E}-5$ & $9.4 \mathrm{E}-6$ & 7.4E-6 & $6.7 \mathrm{E}-6$ \\
\hline 1.00 & $1.7 \mathrm{E}-5$ & $1.2 \mathrm{E}-5$ & $7.7 \mathrm{E}-6$ & $5.5 \mathrm{E}-6$ & $4.8 \mathrm{E}-6$ \\
\hline
\end{tabular}

The design of CHARMS is geared toward minimizing all sources of systematic error associated with refractometry to achieve the highest available precision over all temperature and wavelength space. An extensive discussion of CHARMS' four most significant contributors to index errors has been previously published. ${ }^{4}$ A brief overview follows. At the condition of minimum deviation, the index of refraction of a material is defined by following expression:

$$
n=\frac{\sin \left(\frac{\alpha+\delta}{2}\right)}{\sin \left(\frac{\alpha}{2}\right)}
$$

where $\alpha$ is the angle between refracting faces and $\delta$ is the deviation angle subtended by the refracting light. The apex angle measurement, as detailed in Section 3.0, produces 0.3 arcsecond accuracy. The deviation angle, defined by the angle between an unimpeded beam of light and the refracted beam of light, is recorded by steering both beams of light towards the same detector. The angle of the pickoff mirror used to steer the light is evaluated via absolute rotary encoders with diametrically opposed read stations. The encoders read out the bearing angle accurately to less than $0.00003^{\circ}$ with a peak noise less than $0.00001^{\circ}$. (Identical encoders read the apex measurement's spindle angle when the nulling autocollimator alignment is optimum.) In addition to $\alpha$ and $\delta$, wavelength and temperature are the other dominant sources of error. Moreover, knowledge of wavelength can be a function of wavelength itself - the same is true for temperature being a function of temperature itself. The extent to which both wavelength and temperature influence the uncertainty in a material's index depends on how the index varies with regards to that respective parameter. Therefore, when calculating uncertainty it is important to examine the spectral dispersion $(\mathrm{dn} / \mathrm{d} \lambda)$ and the thermo-optic coefficient $(\mathrm{dn} / \mathrm{dT})$. We extract both of the aforementioned parameters analytically by computing derivatives of the Sellmeier equation. Once the constituent uncertainties are uncovered, one must appropriately incorporate them into the overall uncertainty.

The uncertainties of all prisms in this study at selected wavelengths and temperature are reported in Table 3. In the subsections that follow, each prism will be discussed and compared within the family of glasses determined by Ohara. General statements will be made regarding the optical properties extracted and comparisons to the entire group of prisms will be made. 


\subsection{S-LAH55}

The absolute refractive indices of two prisms of S-LAH55 were measured and deemed to exhibit negligible intra-melt variability. The two sets of measurements were combined into one data file. The absolute index and spectral dispersion of S-LAH55, as generated from Sellemeier coefficients, are depicted in the top two panels of Figure 1. The dispersion is negative and the absolute index becomes lower with decreasing temperature, an effect more clearly visible in the thermo-optic coefficient graph in the lower panel of Figure 1. The temperature dependence of the index of S-LAH55 is more pronounced at the lower wavelength end, possibly due to a noticeable temperature dependence in the material's interband electronic transitions in the ultraviolet range. Table 4 lists values of the quantities plotted in Figure 1 at selected wavelengths.

The temperature-dependent Sellmeier fit of S-LAH55 consisted of 1662 independent deviations and produced an average absolute residual of 4.4E-6. One of the two S-LAH55 prisms was cooled and measured on two separate days.

Figure 1. (From top to bottom) Traces of absolute index, spectral dispersion, and thermo-optic coefficient over the measured spectral range at selected temperatures for S-LAH55.
Table 4. Values of absolute index, spectral dispersion, and thermo-optic coefficient at selected wavelengths for temperatures $120 \mathrm{~K}, 150 \mathrm{~K}, 200 \mathrm{~K}, 250 \mathrm{~K}$, and $300 \mathrm{~K}$ for S-LAH55.

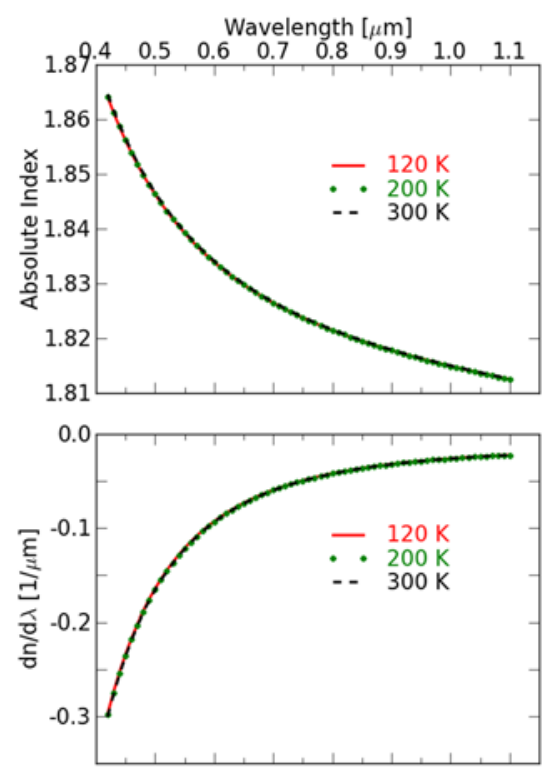

\begin{tabular}{|c|c|c|c|c|c|}
\hline \multicolumn{7}{|c|}{ Refractive index of S-LAH55 } \\
\hline \hline$\lambda[\mu \mathrm{m}]$ & $120 \mathrm{~K}$ & $150 \mathrm{~K}$ & $200 \mathrm{~K}$ & $250 \mathrm{~K}$ & $300 \mathrm{~K}$ \\
\hline 0.50 & 1.84631 & 1.84632 & 1.84637 & 1.84647 & 1.84664 \\
\hline 0.60 & 1.83390 & 1.83390 & 1.83392 & 1.83400 & 1.83412 \\
\hline 0.70 & 1.82646 & 1.82645 & 1.82645 & 1.82651 & 1.82662 \\
\hline 0.80 & 1.82146 & 1.82144 & 1.82144 & 1.82149 & 1.82158 \\
\hline 0.90 & 1.81780 & 1.81778 & 1.81778 & 1.81782 & 1.81790 \\
\hline 1.00 & 1.81492 & 1.81490 & 1.81489 & 1.81493 & 1.81500 \\
\hline 1.10 & 1.81251 & 1.81249 & 1.81248 & 1.81251 & 1.81258 \\
\hline \hline \multicolumn{7}{|c|}{ Spectral dispersion in S-LAH55 } \\
\hline \hline$\lambda[\mu \mathrm{m}]$ & $120 \mathrm{~K}$ & $150 \mathrm{~K}$ & $200 \mathrm{~K}$ & $250 \mathrm{~K}$ & $300 \mathrm{~K}$ \\
\hline 0.50 & -0.1648 & -0.1650 & -0.1654 & -0.1659 & -0.1663 \\
\hline 0.60 & -0.0931 & -0.0932 & -0.0934 & -0.0936 & -0.0939 \\
\hline 0.70 & -0.0597 & -0.0597 & -0.0598 & -0.0600 & -0.0601 \\
\hline 0.80 & -0.0420 & -0.0421 & -0.0421 & -0.0422 & -0.0423 \\
\hline 0.90 & -0.0320 & -0.0321 & -0.0321 & -0.0321 & -0.0322 \\
\hline 1.00 & -0.0261 & -0.0261 & -0.0261 & -0.0261 & -0.0262 \\
\hline 1.10 & -0.0224 & -0.0224 & -0.0224 & -0.0225 & -0.0225 \\
\hline \hline \multicolumn{7}{|c|}{ Thermo-optic coefficient of S-LAH55 } \\
\hline
\end{tabular}

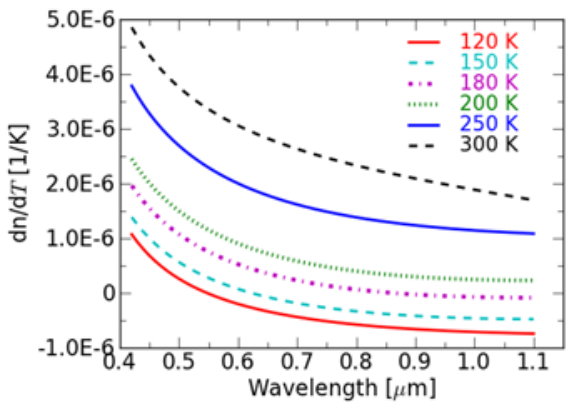

\begin{tabular}{|c|c|c|c|c|c|}
\hline \hline$\lambda[\mu \mathrm{m}]$ & $120 \mathrm{~K}$ & $150 \mathrm{~K}$ & $200 \mathrm{~K}$ & $250 \mathrm{~K}$ & $300 \mathrm{~K}$ \\
\hline 0.50 & $2.56 \mathrm{E}-07$ & $5.60 \mathrm{E}-07$ & $1.49 \mathrm{E}-06$ & $2.69 \mathrm{E}-06$ & $3.76 \mathrm{E}-06$ \\
\hline 0.60 & $-2.04 \mathrm{E}-07$ & $6.90 \mathrm{E}-08$ & $9.00 \mathrm{E}-07$ & $2.00 \mathrm{E}-06$ & $3.06 \mathrm{E}-06$ \\
\hline 0.70 & $-4.42 \mathrm{E}-07$ & $-1.90 \mathrm{E}-07$ & $5.79 \mathrm{E}-07$ & $1.61 \mathrm{E}-06$ & $2.63 \mathrm{E}-06$ \\
\hline 0.80 & $-5.80 \mathrm{E}-07$ & $-3.38 \mathrm{E}-07$ & $3.96 \mathrm{E}-07$ & $1.38 \mathrm{E}-06$ & $2.33 \mathrm{E}-06$ \\
\hline 0.90 & $-6.64 \mathrm{E}-07$ & $-4.21 \mathrm{E}-07$ & $2.94 \mathrm{E}-07$ & $1.23 \mathrm{E}-06$ & $2.09 \mathrm{E}-06$ \\
\hline 1.00 & $-7.15 \mathrm{E}-07$ & $-4.65 \mathrm{E}-07$ & $2.43 \mathrm{E}-07$ & $1.14 \mathrm{E}-06$ & $1.88 \mathrm{E}-06$ \\
\hline 1.10 & $-7.45 \mathrm{E}-07$ & $-4.82 \mathrm{E}-07$ & $2.26 \mathrm{E}-07$ & $1.08 \mathrm{E}-06$ & $1.69 \mathrm{E}-06$ \\
\hline
\end{tabular}




\subsection{S-LAH55v-1}

As highlighted in Section 1.0, the two Ohara prisms of S-LAH55v provided the first-ever opportunity to observe intramelt variability within a set of prisms (i.e., both prisms were formed from the same glass boule). S-LAH55v-1 was found to be systematically lower in absolute index than S-LAH55v2 by $4.0 \mathrm{E}-5$ to $5.0 \mathrm{E}-5$, which is a few times greater than our extracted uncertainty over the majority of our temperature and wavelength range. The absolute index, spectral dispersion, and thermo-optic coefficient of S-LAH55 generated from Sellmeier coefficients are depicted in the top two panels of Figure 1. Values of the aforementioned quantities at selected temperatures and wavelengths are delineated in Table 5. A brief comparison to the previously discussed S-LAH55 parent material is noteworthy. At the short wavelength limit, S-LAH55v-1 is lower in absolute index than S-LAH55 at all temperatures (2.0E-5 at $120 \mathrm{~K}$ and $2.6 \mathrm{E}-$ 5 at $300 \mathrm{~K}$ ). Ironically at the long wavelength limit, S-LAH55v-1 is higher than S-LAH55 by $2.1 \mathrm{E}-5$ at $120 \mathrm{~K}$ and 1.8 $\mathrm{E}-5$ at $300 \mathrm{~K}$. The crossover wavelength is approximately $0.95 \mu \mathrm{m}$ at $120 \mathrm{~K}$ and shifts to $1.005 \mu \mathrm{m}$ at $300 \mathrm{~K}$. SLAH55v-1 exhibits a greater spread in the computed thermo-optic coefficient as compared to S-LAH55.

The temperature-dependent Sellmeier fit of S-LAH55v-1 consisted of 435 independent deviations and produced an average absolute residual of 3.7E-6. One of the two S-LAH55 prisms was cooled and measured on two separate days.

Figure 2. (From top to bottom) Traces of absolute index, spectral dispersion, and thermo-optic coefficient over the measured spectral range at selected temperatures for S-LAH55v-1.
Table 5. Values of absolute index, spectral dispersion, and thermo-optic coefficient at selected wavelengths for temperatures $120 \mathrm{~K}, 150 \mathrm{~K}, 200 \mathrm{~K}, 250 \mathrm{~K}$, and $300 \mathrm{~K}$ for S-LAH55v-1.

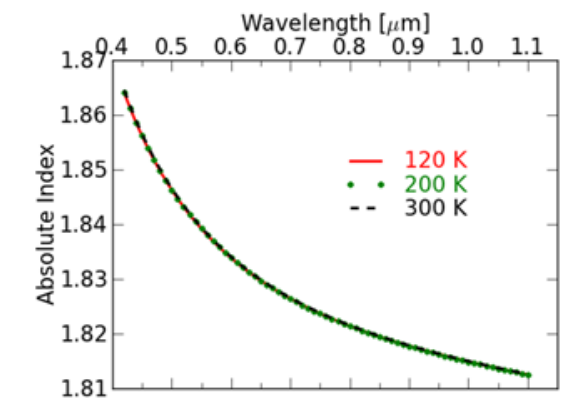

\begin{tabular}{|c|c|c|c|c|c|}
\hline \multicolumn{7}{|c|}{ Refractive index of S-LAH55v-1 } \\
\hline \hline$\lambda[\mu \mathrm{m}]$ & $120 \mathrm{~K}$ & $150 \mathrm{~K}$ & $200 \mathrm{~K}$ & $250 \mathrm{~K}$ & $300 \mathrm{~K}$ \\
\hline 0.50 & 1.84627 & 1.84628 & 1.84632 & 1.84642 & 1.84659 \\
\hline 0.60 & 1.83386 & 1.83385 & 1.83387 & 1.83393 & 1.83407 \\
\hline 0.70 & 1.82641 & 1.82640 & 1.82640 & 1.82645 & 1.82656 \\
\hline 0.80 & 1.82143 & 1.82141 & 1.82141 & 1.82144 & 1.82154 \\
\hline 0.90 & 1.81778 & 1.81777 & 1.81775 & 1.81779 & 1.81787 \\
\hline 1.00 & 1.81492 & 1.81490 & 1.81489 & 1.81492 & 1.81500 \\
\hline 1.10 & 1.81253 & 1.81252 & 1.81250 & 1.81252 & 1.81260 \\
\hline
\end{tabular}

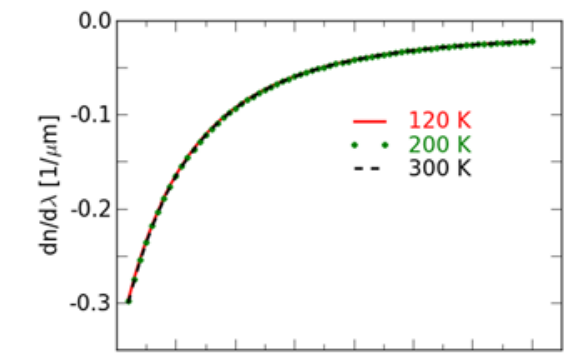

\begin{tabular}{|c|c|c|c|c|c|}
\hline \multicolumn{7}{|c|}{ Spectral dispersion in S-LAH55v-1 } \\
\hline \hline$\lambda[\mu \mathrm{m}]$ & $120 \mathrm{~K}$ & $150 \mathrm{~K}$ & $200 \mathrm{~K}$ & $250 \mathrm{~K}$ & $300 \mathrm{~K}$ \\
\hline 0.50 & -0.1651 & -0.1652 & -0.1656 & -0.1660 & -0.1666 \\
\hline 0.60 & -0.0931 & -0.0932 & -0.0934 & -0.0936 & -0.0939 \\
\hline 0.70 & -0.0596 & -0.0596 & -0.0597 & -0.0599 & -0.0600 \\
\hline 0.80 & -0.0419 & -0.0419 & -0.0420 & -0.0421 & -0.0422 \\
\hline 0.90 & -0.0319 & -0.0319 & -0.0319 & -0.0320 & -0.0321 \\
\hline 1.00 & -0.0259 & -0.0259 & -0.0259 & -0.0259 & -0.0260 \\
\hline 1.10 & -0.0222 & -0.0222 & -0.0222 & -0.0222 & -0.0223 \\
\hline
\end{tabular}

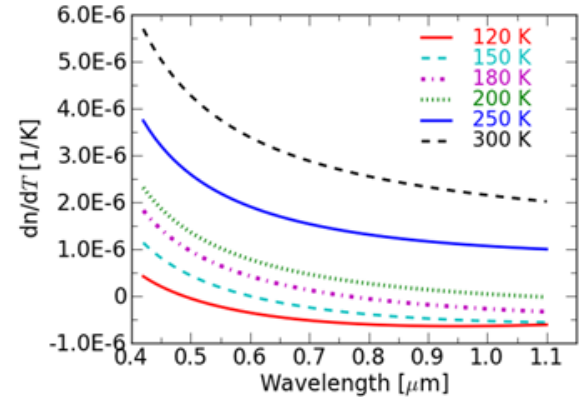

Thermo-optic coefficient of S-LAH55v-1

\begin{tabular}{|c|c|c|c|c|c|}
\hline \hline$\lambda[\mu \mathrm{m}]$ & $120 \mathrm{~K}$ & $150 \mathrm{~K}$ & $200 \mathrm{~K}$ & $250 \mathrm{~K}$ & $300 \mathrm{~K}$ \\
\hline 0.50 & $-5.50 \mathrm{E}-08$ & $4.35 \mathrm{E}-07$ & $1.36 \mathrm{E}-06$ & $2.59 \mathrm{E}-06$ & $4.27 \mathrm{E}-06$ \\
\hline 0.60 & $-3.60 \mathrm{E}-07$ & $-4.00 \mathrm{E}-09$ & $7.78 \mathrm{E}-07$ & $1.90 \mathrm{E}-06$ & $3.38 \mathrm{E}-06$ \\
\hline 0.70 & $-5.23 \mathrm{E}-07$ & $-2.48 \mathrm{E}-07$ & $4.60 \mathrm{E}-07$ & $1.53 \mathrm{E}-06$ & $2.88 \mathrm{E}-06$ \\
\hline 0.80 & $-6.08 \mathrm{E}-07$ & $-3.94 \mathrm{E}-07$ & $2.63 \mathrm{E}-07$ & $1.31 \mathrm{E}-06$ & $2.55 \mathrm{E}-06$ \\
\hline 0.90 & $-6.43 \mathrm{E}-07$ & $-4.83 \mathrm{E}-07$ & $1.32 \mathrm{E}-07$ & $1.16 \mathrm{E}-06$ & $2.32 \mathrm{E}-06$ \\
\hline 1.00 & $-6.42 \mathrm{E}-07$ & $-5.36 \mathrm{E}-07$ & $4.00 \mathrm{E}-08$ & $1.06 \mathrm{E}-06$ & $2.15 \mathrm{E}-06$ \\
\hline 1.10 & $-6.14 \mathrm{E}-07$ & $-5.64 \mathrm{E}-07$ & $-2.50 \mathrm{E}-08$ & $9.96 \mathrm{E}-07$ & $2.01 \mathrm{E}-06$ \\
\hline
\end{tabular}




\subsection{S-LAH55v-2}

The S-LAH55v-2 prism studied was found to be systematically higher (4.0E-5 to 5.0E-5) than S-LAH55v-1 over the entire wavelength and temperature range, and hence deemed to exhibit intra-melt variability. (Uncertainty values and systematic leveling between index curves are the primary factors used to determine the existence of intra-melt variability.) The S-LAH55v-2 absolute index is also higher than the parent S-LAH55 for all wavelengths and temperatures measured. Interestingly, the calculated thermo-optic coefficient traces of S-LAH55v-2 for temperatures $120 \mathrm{~K}$ and $150 \mathrm{~K}$ converge between 0.6 and $0.9 \mu \mathrm{m}$ and diverge at the long and short wavelength limits.

The temperature-dependent Sellmeier fit of S-LAH55v-2 consisted of 739 independent deviations and produced an average absolute residual of 3.6E-6.

Figure 3. (From top to bottom) Traces of absolute index, spectral dispersion, and thermo-optic coefficient over the measured spectral range at selected temperatures for S-LAH55v-2.
Table 6. Values of absolute index, spectral dispersion, and thermo-optic coefficient at selected wavelengths for temperatures $120 \mathrm{~K}, 150 \mathrm{~K}, 200 \mathrm{~K}, 250 \mathrm{~K}$, and $300 \mathrm{~K}$ for S-LAH55v-2.

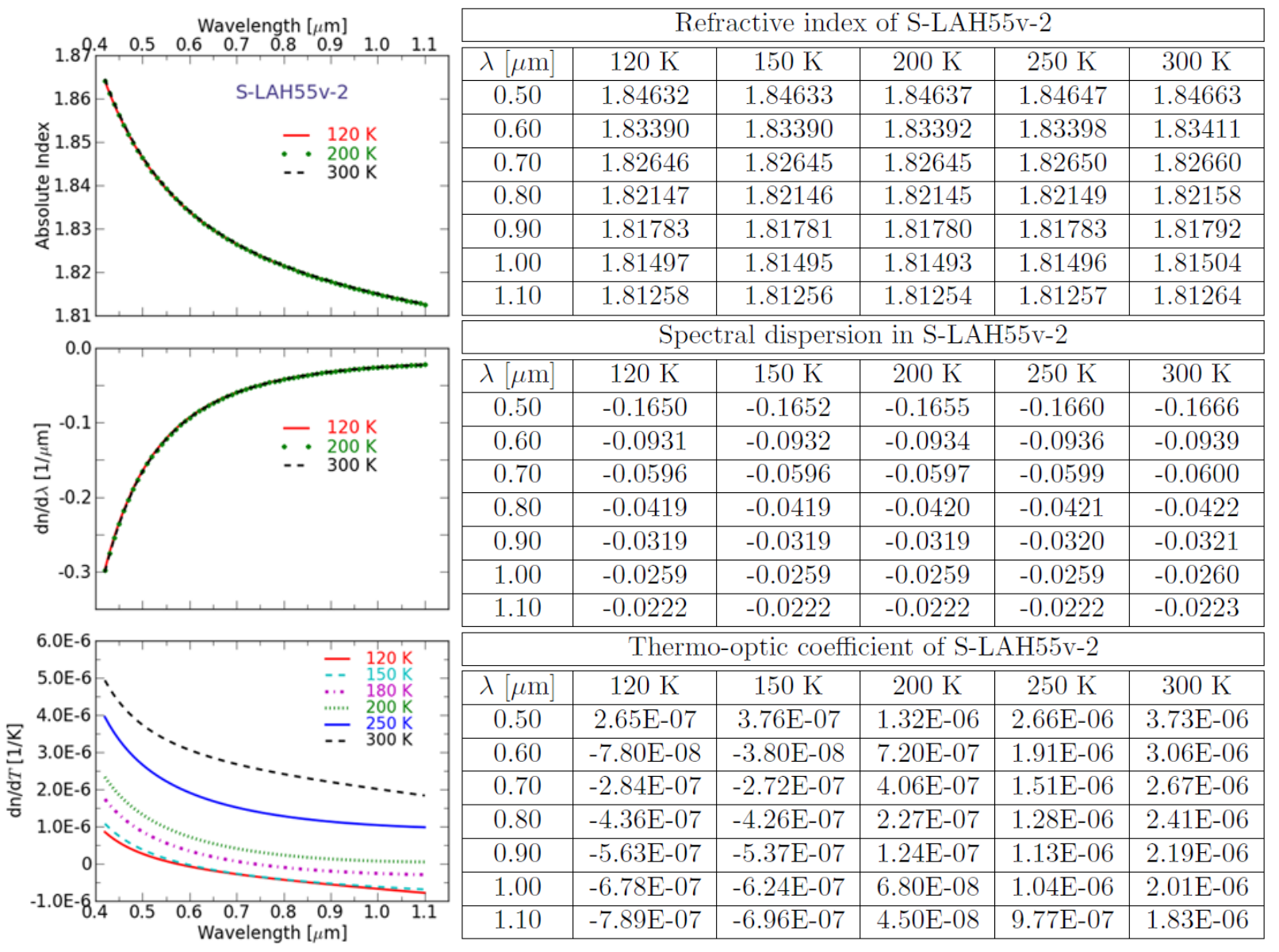




\subsection{S-LAH59}

One of the S-LAH59 prisms was subject to two full cool-downs and the other was measured extensively at roomtemperature. Comparing room-temperature absolute index and dispersion values, we conclusively determined that both S-LAH59 prisms were approximately identical. According to the Ohara naming convention of glasses, ${ }^{5}$ S-LAH59 and S-LAH55 are very similar, yet they are grouped into two different families of glasses (55 vs 59) within the environmentally safe (hence the leading "S") subset. Both prisms contain the same two salient elements, hence the "LA" commonality. The presumable similarities motivate the following comparison: S-LAH59 has an overall lower absolute index and less dispersion (top and middle panels of Figure 4) than the S-LAH55 glass family. The computed thermo-optic coefficient, depicted in the lower panel of Figure 4, is nearly exclusively positive except for the long wavelength range near $150 \mathrm{~K}$. Furthermore, the thermo-optic coefficient at $120 \mathrm{~K}$ begins to rise non-uniformly at all wavelengths, crossing both the $150 \mathrm{~K}$ trace at $\sim 0.715 \mu \mathrm{m}$ and the $180 \mathrm{~K}$ trace at $0.98 \mu \mathrm{m}$. Selected data points defining the curves in Figure 4 are listed in Table 7.

The temperature-dependent Sellmeier fit of S-LAH59 consisted of 764 independent deviations and an average absolute residual of 3.6E-6, which is in the same range of fit quality as the S-LAH55 family.

Figure 4. (From top to bottom) Traces of absolute index, spectral dispersion, and thermo-optic coefficient over the measured spectral range at selected temperatures for S-LAH59.
Table 7. Values of absolute index, spectral dispersion, and thermo-optic coefficient at selected wavelengths for temperatures $120 \mathrm{~K}, 150 \mathrm{~K}, 200 \mathrm{~K}, 250 \mathrm{~K}$, and $300 \mathrm{~K}$ for S-LAH59.

\begin{tabular}{|c|c|c|c|c|c|c|c|}
\hline & {$[\mu \mathrm{m}]$} & & & fractive in & $\mathrm{x}$ of S-LA & 59 & \\
\hline 1.85 .4 & 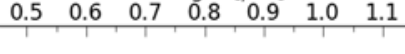 & $\overline{\lambda \lambda[\mu \mathrm{m}]}$ & $120 \mathrm{~K}$ & $150 \mathrm{~K}$ & $200 \mathrm{~K}$ & $250 \mathrm{~K}$ & $300 \mathrm{~K}$ \\
\hline 1.84 & S-LAH59 & 0.50 & 1.82618 & 1.82621 & 1.82628 & 1.82641 & 1.82660 \\
\hline$\underset{0}{0}$ & $120 \mathrm{~K}$ & 0.60 & 1.81506 & 1.81508 & 1.81513 & 1.81523 & 1.81538 \\
\hline & $\begin{array}{l}200 \mathrm{~K} \\
300 \mathrm{~K}\end{array}$ & 0.70 & 1.80833 & 1.80834 & 1.80838 & 1.80846 & 1.80860 \\
\hline & & 0.80 & 1.80380 & 1.80380 & 1.80383 & 1.80391 & 1.80403 \\
\hline 葛 1.81 & & 0.90 & 1.80047 & 1.80047 & 1.80049 & 1.80056 & 1.80068 \\
\hline 1.80 & & 1.00 & 1.79784 & 1.79784 & 1.79786 & 1.79793 & 1.79804 \\
\hline & & 1.10 & 1.79564 & 1.79565 & 1.79566 & 1.79572 & 1.79583 \\
\hline 08 & & & & ctral dispe & ion in S-I & H59 & \\
\hline & & $\lambda[\mu \mathrm{m}]$ & $120 \mathrm{~K}$ & $150 \mathrm{~K}$ & $200 \mathrm{~K}$ & $250 \mathrm{~K}$ & $300 \mathrm{~K}$ \\
\hline & & 0.50 & -0.1470 & -0.1471 & -0.1475 & -0.1479 & -0.1484 \\
\hline & $\begin{array}{r}120 \mathrm{~K} \\
. \cdot 200 \mathrm{~K}\end{array}$ & 0.60 & -0.0839 & -0.0840 & -0.0842 & -0.0844 & -0.0846 \\
\hline & $300 \mathrm{~K}$ & 0.70 & -0.0540 & -0.0541 & -0.0542 & -0.0543 & -0.0545 \\
\hline & & 0.80 & -0.0382 & -0.0382 & -0.0383 & -0.0384 & -0.0385 \\
\hline & & 0.90 & -0.0292 & -0.0292 & -0.0292 & -0.0293 & -0.0294 \\
\hline & & 1.00 & -0.0238 & -0.0238 & -0.0238 & -0.0239 & -0.0239 \\
\hline-0.3 & + & 1.10 & -0.0205 & -0.0205 & -0.0205 & -0.0205 & -0.0206 \\
\hline $6.0 \mathrm{E}-6$ & & & The & -optic cc & icient of & LAH59 & \\
\hline & $\cdots \quad 180 \mathrm{~K}$ & $\lambda[\mu \mathrm{m}]$ & $120 \mathrm{~K}$ & $150 \mathrm{~K}$ & $200 \mathrm{~K}$ & $250 \mathrm{~K}$ & $300 \mathrm{~K}$ \\
\hline & $-250 \mathrm{~K}$ & 0.50 & $6.81 \mathrm{E}-07$ & $1.05 \mathrm{E}-06$ & $2.05 \mathrm{E}-06$ & $3.17 \mathrm{E}-06$ & $4.50 \mathrm{E}-06$ \\
\hline $3.0 \mathrm{E}=6$ & & 0.60 & $4.35 \mathrm{E}-07$ & $6.18 \mathrm{E}-07$ & $1.51 \mathrm{E}-06$ & $2.52 \mathrm{E}-06$ & $3.70 \mathrm{E}-06$ \\
\hline$E-6$ & & 0.70 & $3.47 \mathrm{E}-07$ & $3.69 \mathrm{E}-07$ & $1.21 \mathrm{E}-06$ & $2.17 \mathrm{E}-06$ & $3.26 \mathrm{E}-06$ \\
\hline $1.0 \mathrm{E}-6$ & & 0.80 & $3.46 \mathrm{E}-07$ & $2.11 \mathrm{E}-07$ & $1.03 \mathrm{E}-06$ & $1.97 \mathrm{E}-06$ & $2.97 \mathrm{E}-06$ \\
\hline 0.0 & & 0.90 & $3.99 \mathrm{E}-07$ & $1.01 \mathrm{E}-07$ & $9.08 \mathrm{E}-07$ & $1.83 \mathrm{E}-06$ & $2.78 \mathrm{E}-06$ \\
\hline & & 1.00 & $4.91 \mathrm{E}-07$ & $1.90 \mathrm{E}-08$ & $8.25 \mathrm{E}-07$ & $1.74 \mathrm{E}-06$ & $2.62 \mathrm{E}-06$ \\
\hline & $\begin{array}{lllll}0.6 & 0.7 & 0.8 & 0.9 & 1.0 \\
\text { Wavelength }[\mu \mathrm{m}] & \end{array}$ & 1.10 & $6.12 \mathrm{E}-07$ & $-4.70 \mathrm{E}-08$ & $7.65 \mathrm{E}-07$ & $1.67 \mathrm{E}-06$ & $2.49 \mathrm{E}-06$ \\
\hline
\end{tabular}




\subsection{S-TIH14}

S-TIH14 represents another prism measured with a "high" refractive index (according to the Ohara glass catalog) as signified by the " $\mathrm{H}$ " as the fourth letter in the name, although the two most essential constituent materials in the glass vary from the previous two prisms (TI vs LA). Similar to S-LAH59, only one prism of S-TIH14 was cooled to base temperature, so the room-temperature data was used to verify insignificant intra-melt variability. Compared to S-LAH55 and S-LAH59 prisms, S-TIH14 was measured to have a greater spectra dispersion (more negative) throughout the entire wavelength and temperature range (see Figure 5 middle panel). The thermo-optic coefficient of S-TIH14 (lower panel of Figure 5) begins to decrease with decreasing temperature; however, the trend is not monotonic. At the long wavelength an upturn in the thermo-optic coefficient is evident at $150 \mathrm{~K}$. At $120 \mathrm{~K}$ the trace of the thermo-optic coefficient as a function of wavelength has increased non-uniformly to cross the following temperature traces: $150 \mathrm{~K}$ at $0.55 \mu \mathrm{m}, 180 \mathrm{~K}$ at $0.72 \mu \mathrm{m}, 200 \mathrm{~K}$ at $0.85 \mu \mathrm{m}$, and $250 \mathrm{~K}$ at $1.09 \mu \mathrm{m}$. Table 8 contains selected values of the quantities plotted in Figure 5.

The temperature-dependent Sellmeier fitting of S-TIH14 consisted of 680 independent deviations and an average absolute residual of 5.2E-6. The higher absolute average residual from Sellmeier fitting of S-TIH14 compared to SLAH55, S-LAH55v and S-LAH59 is a direct consequence of the greater dispersion in the glass.

Figure 5. (From top to bottom) Traces of absolute index, spectral dispersion, and thermo-optic coefficient over the measured spectral range at selected temperatures for S-TIH14.
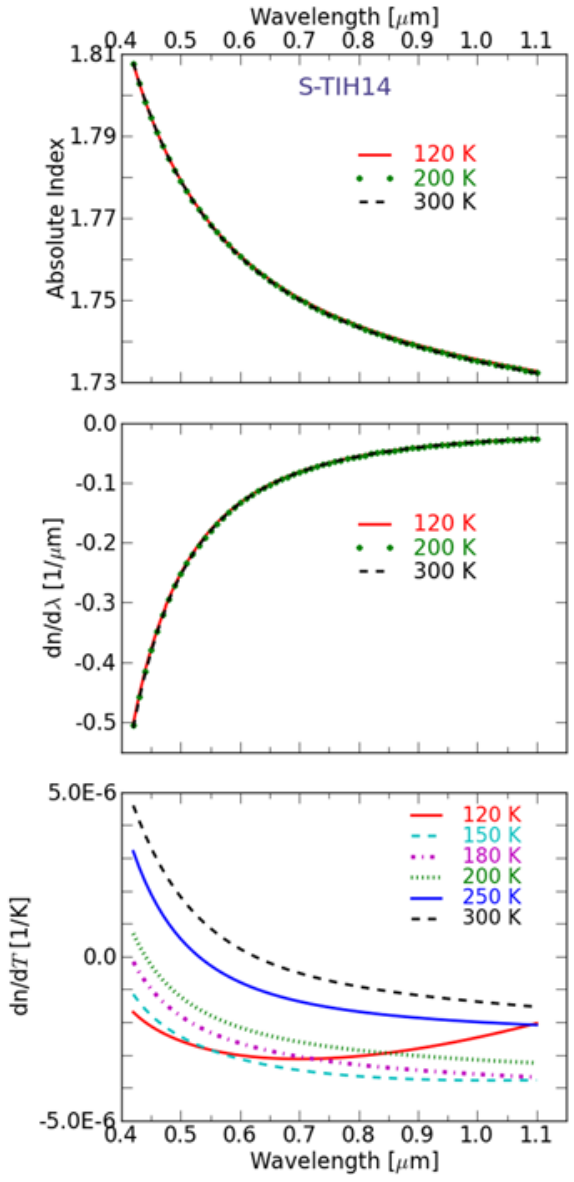

Table 8. Values of absolute index, spectral dispersion, and thermo-optic coefficient at selected wavelengths for temperatures $120 \mathrm{~K}, 150 \mathrm{~K}, 200 \mathrm{~K}, 250 \mathrm{~K}$, and $300 \mathrm{~K}$ for S-TIH14.

\begin{tabular}{|c|c|c|c|c|c|}
\hline \multicolumn{7}{|c|}{ Refractive index of S-TIH14 } \\
\hline \hline$\lambda[\mu \mathrm{m}]$ & $120 \mathrm{~K}$ & $150 \mathrm{~K}$ & $200 \mathrm{~K}$ & $250 \mathrm{~K}$ & $300 \mathrm{~K}$ \\
\hline 0.50 & 1.77920 & 1.77912 & 1.77902 & 1.77900 & 1.77907 \\
\hline 0.60 & 1.76088 & 1.76079 & 1.76065 & 1.76058 & 1.76057 \\
\hline 0.70 & 1.75047 & 1.75037 & 1.75021 & 1.75012 & 1.75007 \\
\hline 0.80 & 1.74378 & 1.74368 & 1.74351 & 1.74340 & 1.74334 \\
\hline 0.90 & 1.73908 & 1.73898 & 1.73881 & 1.73869 & 1.73861 \\
\hline 1.00 & 1.73554 & 1.73544 & 1.73526 & 1.73514 & 1.73505 \\
\hline 1.10 & 1.73271 & 1.73262 & 1.73243 & 1.73230 & 1.73221 \\
\hline \hline \multicolumn{7}{|c|}{ Spectral dispersion in S-TIH14 } \\
\hline \hline$\lambda[\mu \mathrm{m}]$ & $120 \mathrm{~K}$ & $150 \mathrm{~K}$ & $200 \mathrm{~K}$ & $250 \mathrm{~K}$ & $300 \mathrm{~K}$ \\
\hline 0.50 & -0.2514 & -0.2517 & -0.2523 & -0.2531 & -0.2543 \\
\hline 0.60 & -0.1330 & -0.1331 & -0.1334 & -0.1337 & -0.1342 \\
\hline 0.70 & -0.0814 & -0.0814 & -0.0816 & -0.0818 & -0.0820 \\
\hline 0.80 & -0.0551 & -0.0551 & -0.0551 & -0.0553 & -0.0554 \\
\hline 0.90 & -0.0402 & -0.0402 & -0.0403 & -0.0403 & -0.0404 \\
\hline 1.00 & -0.0313 & -0.0313 & -0.0313 & -0.0314 & -0.0314 \\
\hline 1.10 & -0.0258 & -0.0257 & -0.0257 & -0.0258 & -0.0258 \\
\hline \hline \multicolumn{7}{|c|}{ Thermo-optic coefficient of S-TIH14 } \\
\hline \hline$\lambda[\mu \mathrm{m}]$ & $120 \mathrm{~K}$ & $150 \mathrm{~K}$ & $200 \mathrm{~K}$ & $250 \mathrm{~K}$ & $300 \mathrm{~K}$ \\
\hline 0.50 & $-2.57 \mathrm{E}-06$ & $-2.44 \mathrm{E}-06$ & $-1.23 \mathrm{E}-06$ & $5.33 \mathrm{E}-07$ & $1.81 \mathrm{E}-06$ \\
\hline 0.60 & $-3.01 \mathrm{E}-06$ & $-3.12 \mathrm{E}-06$ & $-2.16 \mathrm{E}-06$ & $-7.86 \mathrm{E}-07$ & $2.31 \mathrm{E}-07$ \\
\hline 0.70 & $-3.12 \mathrm{E}-06$ & $-3.47 \mathrm{E}-06$ & $-2.60 \mathrm{E}-06$ & $-1.37 \mathrm{E}-06$ & $-5.09 \mathrm{E}-07$ \\
\hline 0.80 & $-3.04 \mathrm{E}-06$ & $-3.65 \mathrm{E}-06$ & $-2.86 \mathrm{E}-06$ & $-1.68 \mathrm{E}-06$ & $-9.19 \mathrm{E}-07$ \\
\hline 0.90 & $-2.81 \mathrm{E}-06$ & $-3.74 \mathrm{E}-06$ & $-3.03 \mathrm{E}-06$ & $-1.87 \mathrm{E}-06$ & $-1.18 \mathrm{E}-06$ \\
\hline 1.00 & $-2.47 \mathrm{E}-06$ & $-3.78 \mathrm{E}-06$ & $-3.15 \mathrm{E}-06$ & $-2.00 \mathrm{E}-06$ & $-1.38 \mathrm{E}-06$ \\
\hline 1.10 & $-2.04 \mathrm{E}-06$ & $-3.77 \mathrm{E}-06$ & $-3.25 \mathrm{E}-06$ & $-2.09 \mathrm{E}-06$ & $-1.53 \mathrm{E}-06$ \\
\hline
\end{tabular}




\subsection{S-NPH2}

S-NPH2 is the last "high" refractive index prism reported in this paper. The absolute index of S-NPH2, plotted in the top panel of Figure 6, is significantly higher than the S-TIH14, S-LAH59, and S-LAH55 prisms. The spectral dispersion (middle panel Figure 6) is close to double that of S-TIH14 over the whole wavelength and temperature range. The thermo-optic coefficient of S-NPH2 (bottom panel of Figure 6) is also vastly dynamic when compared to the other high-index prisms. S-NPH2 has the highest overall uncertainties of all prisms reported (cf. Table 3) owing to its high index, high spectral dispersion, and high thermo-optic coefficient. Table 9 contains values of the optical properties plotted in Figure 6 at discrete wavelengths and temperatures.

The temperature-dependent Sellmeier fitting encompassed 2561 independent index measurement and yielded an average absolute residual of 7.1E-6. We were able to verify that the two prisms of S-NPH2 exhibited no intra-melt variability. Due to our higher uncertainty of S-NPH2, the comparison of the two prisms motivates an elaboration. The difference between the two measurement sets at the short wavelength limit, where our uncertainty is consistently greater, is no more than about $2.5 \mathrm{E}-5$ where our uncertainty is $\sim 7 \mathrm{E}-5$. At the long wavelength limit $(\sim 1 \mu \mathrm{m})$ the prisms match to the $1 \mathrm{E}-5$ level where our uncertainty is nearly $2 \mathrm{E}-5$.

Figure 6. (From top to bottom) Traces of absolute index, spectral dispersion, and thermo-optic coefficient over the measured spectral range at selected temperatures for S-NPH2.
Table 9. Values of absolute index, spectral dispersion, and thermo-optic coefficient at selected wavelengths for temperatures $120 \mathrm{~K}, 150 \mathrm{~K}, 200 \mathrm{~K}, 250 \mathrm{~K}$, and $300 \mathrm{~K}$ for S-NPH2.

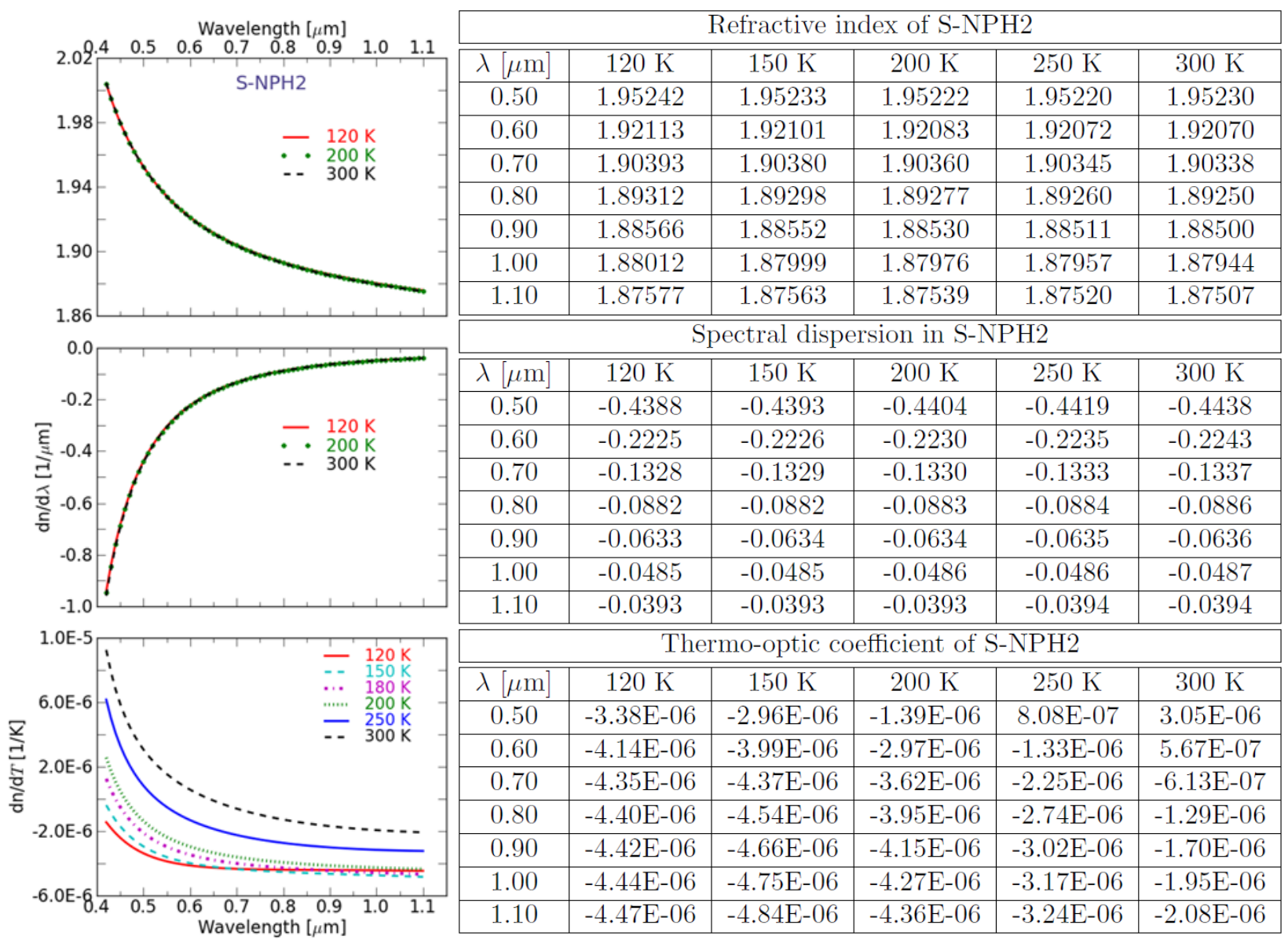




\subsection{S-LAM3}

Two prisms of S-LAM3 were measured over the full wavelength and temperature spectrum. Both prisms of S-LAM3 produced nearly identical absolute index spectra. S-LAM3 represents the first "medium" index prism according to the Ohara glass catalog nomenclature. Figure 6 depicts the absolute index, spectral dispersion, and thermo-optic coefficient respectively. S-LAM3 exhibits a weaker spectral dispersion as compared to the group of high index prisms reported in sections 4.1-4.6. The thermo-optic coefficient is negative for all wavelengths and temperatures. At $154 \mathrm{~K}$ each wavelength simultaneously has a minimum in its $\mathrm{dn} / \mathrm{dT}$ value, and it subsequently begins to increase towards zero. Temperature dependence of the absolute index can be observed at long wavelengths in the top panel plot of Figure 6 .

The temperature-dependent Sellmeier fitting of S-LAM3 involved 1811 independent index measurements and resulted in an average absolute residual of 3.7E-6. The combined index data fit for S-LAM3 was comprised of three separate cooldowns to base temperature to affirm systematics.

Figure 6. (From top to bottom) Traces of absolute index, spectral dispersion, and thermo-optic coefficient over the measured spectral range at selected temperatures for S-LAM3.
Table 9. Values of absolute index, spectral dispersion, and thermo-optic coefficient at selected wavelengths for temperatures $120 \mathrm{~K}, 150 \mathrm{~K}, 200 \mathrm{~K}, 250 \mathrm{~K}$, and $300 \mathrm{~K}$ for S-LAM3.

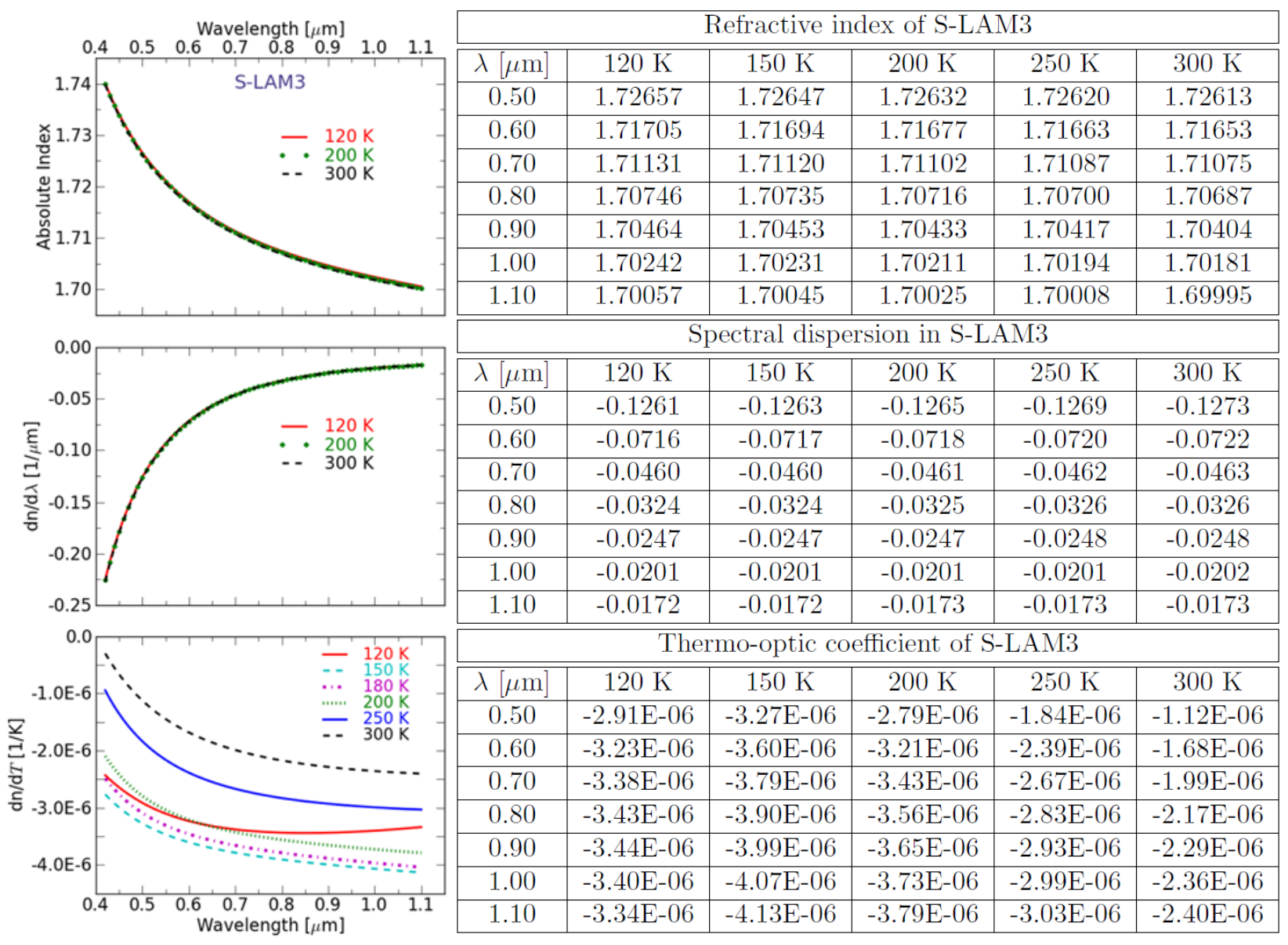




\subsection{S-NBM51}

The absolute index, spectral dispersion, and thermo-optic coefficient of S-NMB51 are presented in Figure 7. S-NBM51 represents another "medium" index prism from Ohara's glass catalog. The measured absolute index of S-NBM51 is lower than the index of S-LAM3 by roughly $1.0 \mathrm{E}-1$. At $1.1 \mu \mathrm{m}$ and $300 \mathrm{~K}$ the spectral dispersion of S-NBM51 is slightly less negative than S-LAM3; however, the spectral dispersion is observably greater at the short wavelength range of this study. The crossover wavelength in the spectral dispersion curves of S-LAM3 and S-NMB51 at $300 \mathrm{~K}$ can be observed at $1.06 \mu \mathrm{m}$; the crossover wavelength decreases with decreasing temperature. The thermo-optic coefficient exhibits similar behavior to that previously reported in S-TIH14 (subsection 4.5). The $120 \mathrm{~K}$ thermo-optic coefficient exhibits both the lowest values at short wavelength, and exhibits the highest values at long wavelength.

No intra-melt variability was observed between the two prisms of S-NBM51 measured. Table 10 contains choice values of the optical properties plotted in Figure 7. The Sellmeier fitting of S-NBM51 consisted of 575 independent apex measurements and resulted in an average absolute residual of 2.6E-6.

Figure 7. (From top to bottom) Traces of absolute index, spectral dispersion, and thermo-optic coefficient over the measured spectral range at selected temperatures for S-NBM51.
Table 10. Values of absolute index, spectral dispersion, and thermo-optic coefficient at selected wavelengths for temperatures $120 \mathrm{~K}, 150 \mathrm{~K}, 200 \mathrm{~K}, 250 \mathrm{~K}$, and $300 \mathrm{~K}$ for S-NBM51.

\begin{tabular}{|c|c|c|c|c|c|c|}
\hline \multirow{2}{*}{ 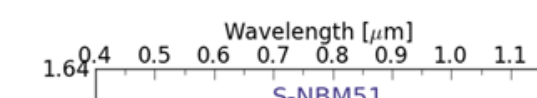 } & \multicolumn{6}{|c|}{ Refractive index of S-NBM51 } \\
\hline & $\lambda[\mu \mathrm{m}]$ & $120 \mathrm{~K}$ & $150 \mathrm{~K}$ & $200 \mathrm{~K}$ & $250 \mathrm{~K}$ & $300 \mathrm{~K}$ \\
\hline \multirow{7}{*}{$\begin{array}{l}-120 \mathrm{~K} \\
\because \quad 200 \mathrm{~K} \\
-300 \mathrm{~K}\end{array}$} & 0.50 & 1.62164 & 1.62164 & 1.62167 & 1.62175 & 1.62189 \\
\hline & 0.60 & 1.61286 & 1.61285 & 1.61286 & 1.61292 & 1.61303 \\
\hline & 0.70 & 1.60755 & 1.60754 & 1.60754 & 1.60759 & 1.60768 \\
\hline & 0.80 & 1.60394 & 1.60393 & 1.60392 & 1.60397 & 1.60405 \\
\hline & 0.90 & 1.60125 & 1.60124 & 1.60123 & 1.60127 & 1.60134 \\
\hline & 1.00 & 1.59908 & 1.59908 & 1.59907 & 1.59910 & 1.59917 \\
\hline & 1.10 & 1.59723 & 1.59724 & 1.59721 & 1.59725 & 1.59732 \\
\hline \multirow{9}{*}{$\begin{array}{l}0.0 \\
.05 \\
.10 \\
.15 \\
.20\end{array}$} & \multicolumn{6}{|c|}{ Spectral dispersion in S-NBM51 } \\
\hline & $\lambda[\mu \mathrm{m}]$ & $120 \mathrm{~K}$ & $150 \mathrm{~K}$ & $200 \mathrm{~K}$ & $250 \mathrm{~K}$ & $300 \mathrm{~K}$ \\
\hline & 0.50 & -0.1165 & -0.1166 & -0.1168 & -0.1172 & -0.1176 \\
\hline & 0.60 & -0.0661 & -0.0661 & -0.0663 & -0.0664 & -0.0666 \\
\hline & 0.70 & -0.0428 & -0.0428 & -0.0429 & -0.0430 & -0.0431 \\
\hline & 0.80 & -0.0307 & -0.0306 & -0.0307 & -0.0307 & -0.0308 \\
\hline & 0.90 & -0.0238 & -0.0238 & -0.0238 & -0.0239 & -0.0239 \\
\hline & 1.00 & -0.0198 & -0.0198 & -0.0198 & -0.0198 & -0.0199 \\
\hline & 1.10 & -0.0175 & -0.0174 & -0.0174 & -0.0174 & -0.0175 \\
\hline \multirow{9}{*}{ 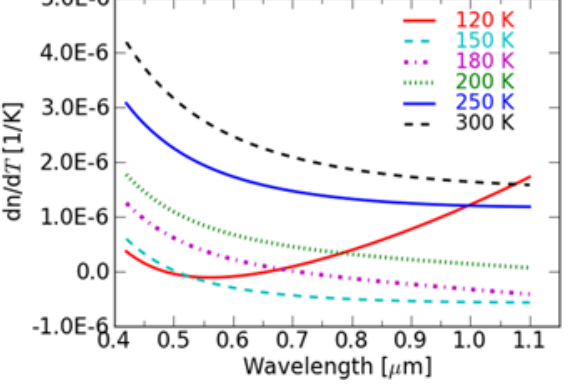 } & \multicolumn{6}{|c|}{ Thermo-optic coefficient of S-NBM51 } \\
\hline & $\lambda[\mu \mathrm{m}]$ & $120 \mathrm{~K}$ & $150 \mathrm{~K}$ & $200 \mathrm{~K}$ & $250 \mathrm{~K}$ & $300 \mathrm{~K}$ \\
\hline & 0.50 & $-4.70 \mathrm{E}-08$ & $1.60 \mathrm{E}-08$ & $1.09 \mathrm{E}-06$ & $2.25 \mathrm{E}-06$ & $3.15 \mathrm{E}-06$ \\
\hline & 0.60 & $-9.50 \mathrm{E}-08$ & $-3.01 \mathrm{E}-07$ & $6.70 \mathrm{E}-07$ & $1.73 \mathrm{E}-06$ & $2.46 \mathrm{E}-06$ \\
\hline & 0.70 & $8.50 \mathrm{E}-08$ & $-4.41 \mathrm{E}-07$ & $4.49 \mathrm{E}-07$ & $1.46 \mathrm{E}-06$ & $2.09 \mathrm{E}-06$ \\
\hline & 0.80 & $3.86 \mathrm{E}-07$ & $-5.10 \mathrm{E}-07$ & $3.12 \mathrm{E}-07$ & $1.32 \mathrm{E}-06$ & $1.86 \mathrm{E}-06$ \\
\hline & 0.90 & $7.68 \mathrm{E}-07$ & $-5.45 \mathrm{E}-07$ & $2.13 \mathrm{E}-07$ & $1.24 \mathrm{E}-06$ & $1.72 \mathrm{E}-06$ \\
\hline & 1.00 & $1.22 \mathrm{E}-06$ & $-5.64 \mathrm{E}-07$ & $1.34 \mathrm{E}-07$ & $1.20 \mathrm{E}-06$ & 1.63E-06 \\
\hline & 1.10 & $1.72 \mathrm{E}-06$ & $-5.72 \mathrm{E}-07$ & $6.40 \mathrm{E}-08$ & $1.18 \mathrm{E}-06$ & $1.58 \mathrm{E}-06$ \\
\hline
\end{tabular}




\subsection{S-PHM52}

S-PHM52 is the final "middle" index prism measured, and the range of index values draws similarities to S-NBM51 (subsection 4.8). The measured absolute index, spectral dispersion, and thermo-optic coefficient of S-PHM52 are plotted in the top, middle, and bottom panels of Figure 8, respectively. Table 11 contains a select number of values of the quantities plotted in Figure 8. The absolute index of S-PHM52 exhibits the strongest temperature dependence of all glasses reported in this paper. The index increases with decreasing temperature across the entire measured wavelength range. S-PHM52 shows a significantly weaker spectral dispersion at all wavelengths and temperatures when compared to S-LAM3 and S-NBM51. S-NBM51 exhibits the greatest (most negative) thermo-optic coefficient of all prisms reported herein, and it is one of only two prisms with an exclusively negative thermo-optic coefficient value over the entire wavelength and temperature range measured (S-LAM3 being the other).

The indices of the two measured prisms of S-PHM52 overlapped indistinguishably. The Sellmeier fitting of S-PHM52 consisted of 613 independent apex measurements and resulted in an average absolute residual of 3.5E-6.

Figure 8. (From top to bottom) Traces of absolute index, spectral dispersion, and thermo-optic coefficient over the measured spectral range at selected temperatures for S-PHM52.
Table 11. Values of absolute index, spectral dispersion, and thermo-optic coefficient at selected wavelengths for temperatures $120 \mathrm{~K}, 150 \mathrm{~K}, 200 \mathrm{~K}, 250 \mathrm{~K}$, and $300 \mathrm{~K}$ for S-PHM52.

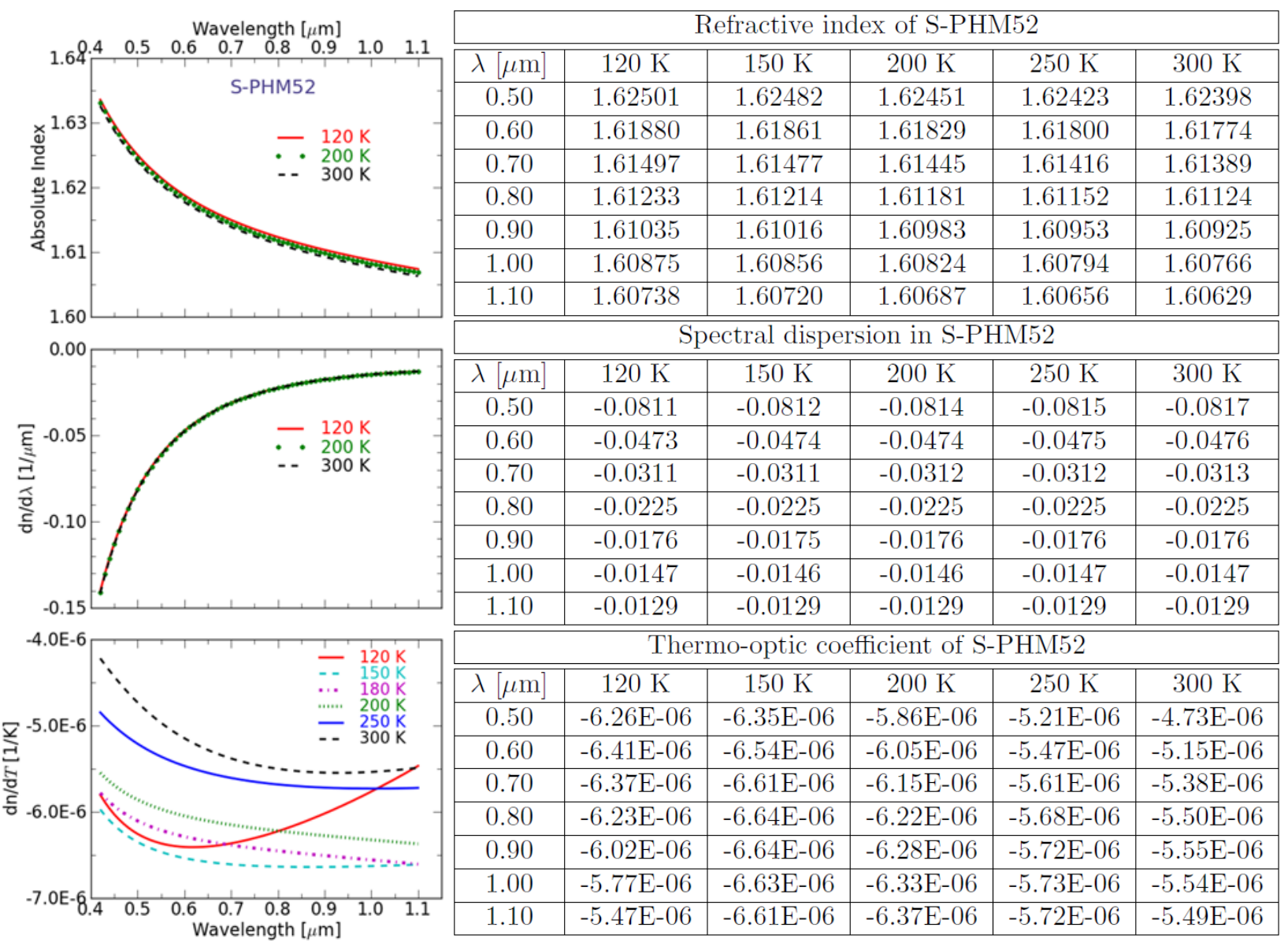




\subsection{DISCUSSION}

There exists minimal index data at cryogenic temperatures in the literature in general. Of the eight glasses reported in this paper we are fortunate that two of these (S-PHM52 and S-TIH14) have previously reported cryogenic refractive indices. ${ }^{6}$ Prior to the cryogenic comparison, it is of interest to first examine our results on all prisms with those published in the Ohara glass catalog. ${ }^{5}$ Index values published by Ohara represent the statistics from many melts of a particular glass type which, considering the lack of high accuracy absolute refractive index measurement of a specific melt, represent expectation values of the index as a function of wavelength. (It should be noted that all Ohara values are quoted at ambient pressure and $25^{\circ} \mathrm{C}$.)

We scaled Ohara's catalog index values to their respective vacuum wavelength values by multiplying the index of refraction they reported by a constant value of 1.00027 . For our comparison, it is most intuitive to plot the index difference between the scaled Ohara value and our CHARMS generated value at $298 \mathrm{~K}$ in the overlap region. The results are shown in Figure 9. An axis break is used because the S-NPH2 prism stands alone as being the most discrepant compared with our measurements (a difference of $\sim 2.5 \mathrm{E}-4$ ). The other prisms fall into an envelope that is as much as 1.1E-4 higher and 5.0E-5 lower than our results. The computed difference in a number of prisms exhibits a downward trend with decreasing wavelength. The trend is presumably a result of a systematic difference between Ohara's measurements and ours. Interestingly, the S-LAH55v-2 prism agrees better with the Ohara catalog S-LAH55v values for all wavelengths above $0.5 \mu \mathrm{m}$.

Figure 9. The difference between Ohara catalog indices (scaled to vacuum) and indices measured on CHARMS at 298 K.

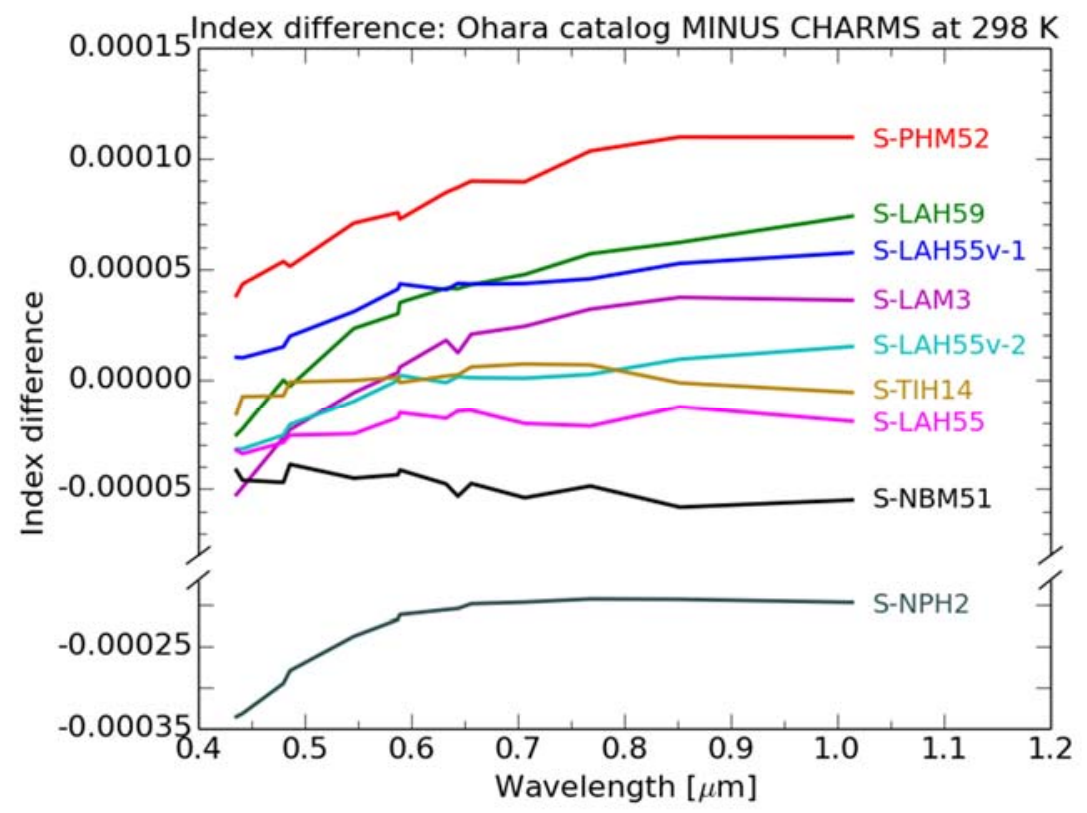

We finally compare our cryogenic index values on S-PHM52 and S-TIH14 to those of Yamamuro et al. ${ }^{6}$ We overlap the results of Yamamura et al. at the following three wavelengths: $1.01398 \mu \mathrm{m}, 0.54607 \mu \mathrm{m}$, and $0.43584 \mu \mathrm{m}$. A similar difference plot is shown for comparison in the right and left panels of Figure 10. The S-TIH14 indices agree better over the range of wavelengths and temperatures when compared to the S-PHM52 indices. Our indices are systematically higher than S-TIH14 indices and lower than S-PHM25 indices. The maximum difference for S-TIH14 is 1.2E-4 observed at $120 \mathrm{~K}$ and $0.43584 \mu \mathrm{m}$. As the wavelength increases, the agreement between S-TIH14 measurements converge towards their minimal values. Conversely, S-PHM52 data agree better at shorter wavelength. The maximum difference is observed at $120 \mathrm{~K}$ and $1.01398 \mu \mathrm{m}$. 

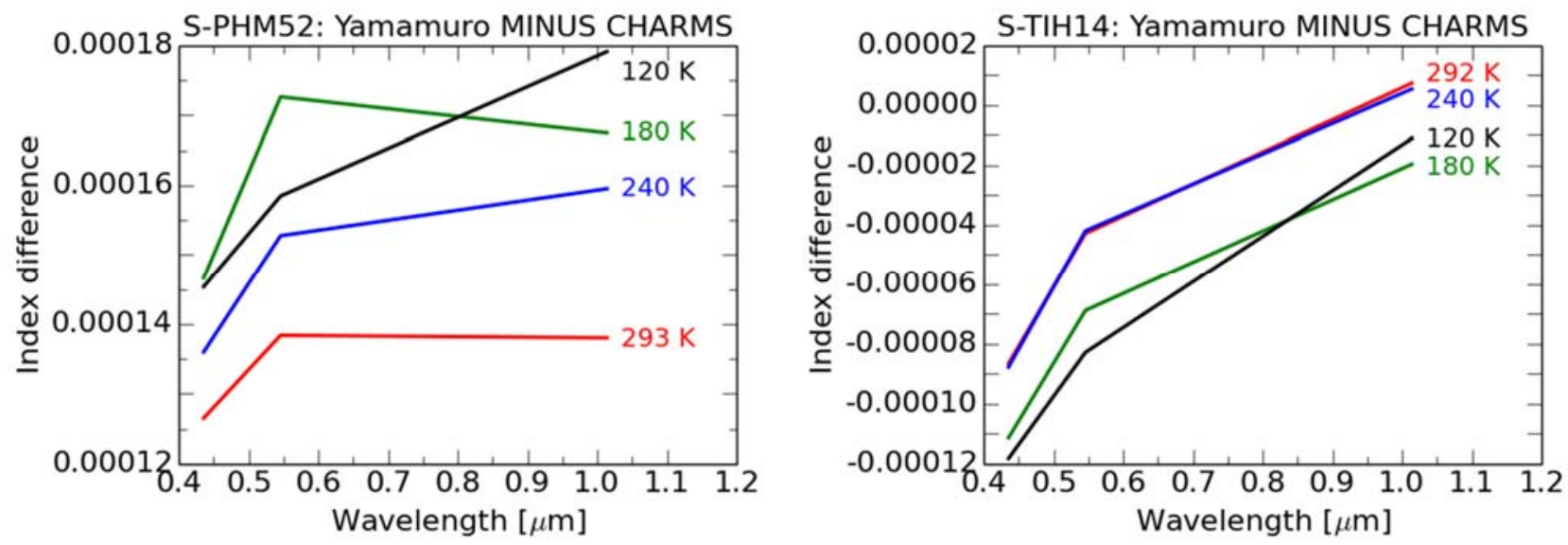

Figure 10. The difference between Yamamuro's indices and CHARMS indices for S-PHM52 (left panel) and S-TIH14 (right panel).

\subsection{CONCLUSION}

We have measured the absolute refractive index of pairs of the following eight Ohara glasses: S-LAH55, S-LAH55V, SLAH59, S-LAM3, S-NBM51, S-NPH2, S-PHM52, and S-TIH14 over the wavelength range 0.416-1.15 um and temperature range $110-310 \mathrm{~K}$. We have fit our individual measured index data sets with a temperature-dependent Sellmeier model expanded to third order. Our fits agree well with the raw index data as evidenced by the average modulus difference between raw data and modeled data ranging from 3.6E-6 to 7.1E-6. We have presented the spectral dispersion, thermo-optic coefficient, and provided a dense temperature-wavelength matrix of index uncertainty values for each prism. The measured optical properties of all prisms were discussed and compared within their Ohara grouping (high and middle). For the first time ever, the CHARMS instrument has detected intra-melt variability (difference between two prisms from the same glass melt) in the S-LAH55v glass family. S-LAH55v-1 was found to be systematically lower in absolute index than S-LAH55v2 by $4.0 \mathrm{E}-5$ to $5.0 \mathrm{E}-5$, which is a few times greater than our extracted uncertainty over the majority of our temperature and wavelength space. Index values of all eight glasses were compared to the reported index values in the Ohara catalog. We observe an average $2.5 \mathrm{E}-4$ difference for the S-NPH2 prism. All other prisms fall into an envelope between 1.1E-4 higher and 5.0E-5 lower than our results. S-PHM52 and STIH14 were compared with cryogenic results in literature. The results agree much closer for S-TIH14, whose difference converges on zero at long wavelength. The S-PHM52 data sets are on average 1.5E-4 discrepant.

\section{REFERENCES}

[1] Leviton, D. B., Frey, B.J., "Design of a cryogenic, high accuracy, absolute prism refractometer for infrared through far ultraviolet optical material," SPIE 4842, 259 (2003), http://dx.doi.org/10.1117/12.459479

[2] Frey, B. J., Leviton, D. B., Henry, R. M., Quijada, M. A., "Cryogenic high-accuracy absolute prism refractometer for infrared through far-ultra-violet optical materials: implementation and initial results," SPIE 5172, 119 (2003),

http://dx.doi.org/10.1117/12.506097

[3] Ricker, G. R., Winn, J. N., Vanderspek, R., Latham, D. W., Bakos, G. A., et al., "Transiting Exoplanet Survey Satellite,” J. Astron. Telesc. Instrum. Syst. 1(1), 014003 (Oct. 24, 2014), http://dx.doi.org/10.1117/1.JATIS.1.1.014003

[4] Leviton, D. B., Frey, B. J., Henry, R. M., "Temperature-dependent refractive index measurements of S-FPL51, S-FTM16, and STIM28 to cryogenic temperatures," SPIE 8863, (2013), http://dx.doi.org/10.1117/12.2024821

[5] Ohara Optical Glass Catalog, http://www.Oharacorp.com/

[6] Yamamuro, T., et al, "Measurement of refractive indices of 20 optical materials at low temperatures," Optical Engineering, 45(8), (2006), http://dx.doi.org/10.1117/1.2336241 